\title{
Impactos de las medidas de estabilidad presupuestaria en el Sistema de Autonomía y Atención a la Dependencia: retos del futuro
}

\author{
Julia Montserrat Codorniu \\ Doctora en Economía. Investigadora en el ámbito de la protección social \\ <jmontserratc@gmail.com>
}

\begin{abstract}
Norberaren Autonomia Sustatzeko eta
Mendetasunaren Arretarako 39/2006 Legea

herritarren lorpen bat izan zen, izan ere, Estatuak aitortu egin zuen babes publikorako eskubidea izatea mendetasun egoeraren bat bizi eta familia edota ekonomiaren arloko baldintzen ondorioz babes soziala bermatzeko, modu horretan politika sozialen benefizientziaren ikuspegia gainditu egiten zen. Artikulu honek laburbiltzen ditu 20/2012 Errege Dekretuak aurrekontuen egonkortasunerako bideratzen dituen neurrien eraginak. Izan ere, Mendetasunaren Autonomia eta Arretarako Sistemaren iraunkortasuna aitzakia hartuz, 39/2006 Legeak ezarritako babes sozialaren mailan atzerakada ekarri du Dekretu horrek, eta horren bidez, murriztu egin dira onuradunen eskubideak, prestazioek duten arretaren kalitatea eskastu egin da, zerbitzuen izaera merkantilista areagotu da, gutxitu egin da finantzazio publikoa, eta erabiltzaileen zergen ekarpena hazi egin da. Aurrekontuen egonkortasunerako neurrien ondorioz, lehenengo hiru urteotako gastu publikoaren beherakada kalkulatzen da $\mathbf{9 . 0 0 0}$ milioi eurokoa izan dela, hau da, mendetasun moderatua duten pertsonen arretarako urtebeteko gastu osoaren baliokidea da hori, eta GPBaren \% 0'7 inguruko gastua bideratzen da mendetasunaren arretara, 39/2006 Legeak aurreikusitako \% 1etik beherako ehunekoa, eta Europar Batasuneko herrialdeetako mediaren aldean ehuneko puntu bat gutxiago da hori.
\end{abstract}

\section{GAKO-HITZAK:}

Mendetasuna, politika soziala, gastu publikoa, aurrekontuen egonkortasuna.
La Ley 39/2006 de Promoción de la Autonomía Personal y Atención a las Personas en Situación de Dependencia (LAPAD) supuso una conquista de los ciudadanos, al lograr que el Estado reconociera el derecho de las personas en situación de dependencia a ser objeto de protección social pública, asegurando que ninguna persona en dicha situación pudiera quedar desprotegida por circunstancias familiares o económicas, superando la visión benéfica de la política social. El presente artículo sintetiza de los impactos de las medidas de estabilidad presupuestarias lideradas por el Real Decreto Ley 20/2012, que, bajo el pretexto de la sostenibilidad del Sistema de Autonomía y Atención a la Dependencia (SAAD), ha supuesto un retroceso del nivel de protección social definido en la Ley 39/2006, recortando derechos de las personas beneficiarias, rebajando la calidad asistencial de las prestaciones, aumentando la mercantilización de los servicios, disminuyendo la financiación pública y aumentando la presión contributiva de los usuarios. La disminución del gasto público en los tres primeros ejercicios de la aplicación de las medidas de estabilidad presupuestaria se estima en casi $\mathbf{9 . 0 0 0}$ millones de euros, lo que equivale al gasto global de un ejercicio incluyendo la atención a las personas con dependencia moderada, y sitúa el gasto en atención a la dependencia en alrededor del $0,7 \%$ del PIB, por debajo del $1 \%$ proyectado por la LAPAD y un punto porcentual por debajo de la media de los países de la Unión Europea.

\section{PaLABRAS ClaVe:}

Dependencia, política social, gasto público, estabilidad presupuestaria. 


\section{La LAPAD y su refundación en 2012}

La atención a la dependencia se ha convertido en una prioridad social por el crecimiento continuado de personas que, como consecuencia del padecimiento de enfermedades crónicas, procesos patológicos o accidentes sobrevenidos, presenta algún tipo de discapacidad la cual, antes o después, disminuirá su autonomía derivando en una situación de dependencia funcional y, en algunos casos, dependencia funcional y sanitaria a la vez. La prevalencia de la dependencia es mayor en las personas mayores, especialmente a partir de los 80 años, aunque no hay una relación unívoca entre el aumento del número de años de vida y el número de personas con dependencia.

La Unión Europea, ante las proyecciones del envejecimiento masivo que se prevé en el Horizonte 2050, especialmente a partir de la entrada de la generación del baby boom ${ }^{1}$, alertó a los Estados miembros de la necesidad de incorporar políticas públicas de atención a la dependencia con el fin de evitar un incremento del nivel de pobreza o de exclusión social de la población afectada. Aunque la política social es competencia de cada miembro de la UE, lo cierto es que las recomendaciones en materia de modernización económica de la Comisión Europea y una base sociodemográfica relativamente convergente, han presionado en favor de modelos de atención a la dependencia que tienden a un rasgo común, al menos en el grupo de la UE-15: diseño institucional en base a un sistema de cobertura universal (derecho subjetivo), prestaciones mixtas (servicios y prestaciones económicas), descentralizado en cuanto a planificación y gestión (gobiernos regionales y locales), financiación mixta (pública y privada) y una oferta de servicios de responsabilidad pública con gestión pública y privada (Rodríguez Cabrero, 2012).

En la senda de las recomendaciones de la Comisión Europea, España amplió el alcance de la protección social promulgando la Ley 39/2006, de 14 de diciembre, de Promoción de la Autonomía Personal y Atención a las personas en situación de dependencia, conocida como “LAPAD”, que entró en vigor el 1 de enero de 2007. Dicha Ley supone la introducción de un derecho de ciudadanía mediante el cual todas las personas en situación de dependencia "protegible"2 tienen acceso a unas prestaciones adecuadas a su necesidad. Para las Administraciones Públicas supone pasar de presupuestos limitados y distribución de recursos mediante subvenciones a otro sistema donde el presupuesto de atención a la dependencia no puede estar limitado bajo ninguna circunstancia y los créditos presupuestarios deben ser ampliados en el caso de que la demanda de las personas beneficiarias supere las previsiones presupuestarias iniciales.

${ }^{1}$ En España se estima a partir del 2025

2 Para tener derecho a las prestaciones, la persona en situación de dependencia debe ser reconocida como tal según el baremo de valoración de la dependencia establecido en la LAPAD.
La LAPAD es la Ley marco ${ }^{3}$ que regula las condiciones básicas de acceso de las personas beneficiarias a un conjunto de prestaciones mínimas, comunes y garantizadas, para asegurar un trato equitativo a las personas en todos los territorios. Las Administraciones autonómicas son las responsables de ejecutar el mandato de la LAPAD al tener atribuidas las competencias en la gestión de los servicios sociales, donde se encuentra adscrita la atención a la dependencia. La articulación y cooperación entre las políticas públicas de las CC.AA. se realiza a través del Consejo Territorial de Servicios Sociales y del Sistema para la Autónoma y la Atención a la Dependencia, donde están representadas todas las autonomías, el cual aprueba criterios de actuación comunes en todos los territorios, debiendo cada comunidad autónoma trasponer los acuerdos alcanzados a su normativa.

La LAPAD estableció un periodo progresivo de implantación del derecho de los ciudadanos a las prestaciones de la Ley (2007-2015) con el objetivo de regular el impacto asistencial y presupuestario que podía representar en las autonomías la entrada masiva de personas beneficiarias en el Sistema. El plazo previsto de despliegue de la LAPAD se ha visto alterado por el Real Decreto-Ley 20/20124, el cual no sólo ha introducido recortes presupuestarios sino que ha supuesto una reforma integral de la LAPAD, a la vez que pospuso durante tres años, el derecho de entrar en el Sistema a los beneficiarios del Grado 1 (dependencia moderada).

\subsection{La refundación de la LAPAD: RDL 20/2012}

La reforma de la LAPAD se enmarca en un contexto de recrudecimiento de la crisis económica a partir de mediados del 2010 y en un cambio del discurso económico dominante a nivel europeo, el cual es asumido por el Gobierno recién salido de las urnas a finales del 2011. La nueva orientación de la política económica en la salida de la crisis se centra en reforzar la devaluación salarial, la liberalización del mercado laboral y la reducción de los déficits fiscales, mediante la contención del gasto público y el incremento de los impuestos, sustituyendo las anteriores políticas expansivas de gasto que tenían entre sus objetivos contrarrestar los efectos de la crisis en la población afectada.

Los Presupuestos Generales del Estado para $2012^{5}$ y la reforma de las pensiones de la Seguridad Social (Ley $27 / 2011)^{6}$ se presentan como una avanzadilla de

${ }^{3} \mathrm{El}$ art. 49.1 de la Constitución española establece la capacidad del Estado de extender la acción protectora social a todos los ciudadanos.

${ }^{4}$ Real Decreto-Ley 20/2012, de 13 julio, de medidas para garantizar la estabilidad presupuestaria y de fomento de la competitividad. [https://www.boe.es/buscar/act.php?id=BOE-A-2012-9364]

Se destacan las siguientes medidas: congelación de salarios públicos, incremento de los tipos de gravamen del IRPF y del Impuesto sobre bienes inmuebles y, en relación a la LAPAD, se suspende el Nivel acordado.

${ }^{6}$ Ley 27/2011, de 1 de agosto, sobre actualización, adecuación y modernización del sistema de Seguridad Social. Reforma integral 
las reformas del Gobierno que tendrán su máxima expresión en la reforma laboral, en febrero de $2012^{7}$ (flexibilidad, modificación contractual, abaratamiento y ampliación de las causas del despido, restricciones a los convenios colectivos, etc.), y en las medidas para garantizar la estabilidad presupuestaria, en julio de $2012^{8}$, que tienen como objetivo general reducir el gasto público e incrementar los ingresos fiscales. En este paquete de reformas se incluyen los recortes de la LAPAD y otras medidas que repercuten en mayor proporción en las personas más afectadas por la crisis económica (reducciones en prestación desempleo, en los salarios de tramitación de los despidos, en renta básica de emancipación y en una fuerte subida del IVA ${ }^{9}$, entre otras).

El conjunto de las medidas expuestas en el párrafo anterior van a suponer un empobrecimiento de la población en general y un aumento de la desprotección pública ante las situaciones de necesidad de las personas afectadas por la crisis y/o en riesgo de exclusión social. Pero, mientras se recortan gastos para atender los servicios públicos esenciales (sanidad, educación, pensiones, dependencia) y se reduce la protección social de las personas más vulnerables social y económicamente (desempleados, familias con rentas bajas, marginados), el Estado se endeuda para sanear el sector financiero cuyo coste se estima, alrededor de 100.000 millones de euros ${ }^{10}$-entre el $8,5 \%$ y el $9 \%$ del PIB-, con un resultado final negativo para las finanzas públicas, previéndose que un tercio de la inversión no se recuperará ${ }^{11}$ engrosando el déficit público, lo cual muestra el doble rasero en las decisiones del Gobierno para afrontar la crisis fiscal de las finanzas públicas.

El Gobierno contextualiza la reforma de la LAPAD como "urgente" ya que según dice en el preámbulo del RDL 20/2012, su desarrollo “amenaza la sostenibilidad del Sistema, tiene consecuencias perjudiciales para el empleo y perjudica la viabilidad de los sectores productivos relacionados con la dependencia ${ }^{12}$ ". En este contexto de aplicación de medidas antikeynesianas, el Gobierno refunda la LAPAD configurando una "nueva" LAPAD, la cual recorta derechos de las personas beneficiarias, rebaja la oferta y calidad asistencial y reduce el gasto público disminuyendo el presupuesto destinado a la atención a la dependencia e incrementando los ingresos a

de las pensiones conteniendo el incremento de sus importes y eliminado su actualización con la evolución del IPC (índice de precios al consumo).

7 Real Decreto-ley 3/2012, de 10 de febrero, de medidas urgentes para la reforma del mercado laboral.

${ }^{8}$ Real Decreto-ley 20/2012, de13 de julio, de medidas para garantizar la estabilidad presupuestaria y de fomento de la competitividad.

${ }^{9}$ Se eleva el tipo general del $18 \%$ al $21 \%$, el reducido pasa del $8 \%$ al $10 \%$ y se modifica el IVA de algunos productos con IVA reducido que pasaran a tributar al tipo general (asistencia sanitaria y dental; espectáculos i servicios funerarios, entre otros).

${ }^{10} \mathrm{http}$ ://www.lavanguardia.com/economia/20140623/5441030 4294/coste-rescate-banca-espana.html.

${ }^{11}$ El Banco de España calcula en 37.000 millones la deuda que no se recuperará. http://goo.gl/kVmGWi

${ }^{12}$ BOE de 14 de julio de 2012, pg. 50435, segundo párrafo. través de los copagos. La única medida positiva que incluye es la extensión de la prestación de "asistencia personal" a todos los grados de dependencia, cuando antes solo podían solicitarla aquellas personas con dependencia muy grave (Grado 3).

La declaración de principios del RDL 20/2012 en materia de atención a la dependencia es desproporcionada en relación a un gasto que, en 2011, apenas alcanzaba los 6.000 millones de euros, el $0,65 \%$ del PIB, y que el desarrollo normal de la LAPAD preveía alcanzase el $1 \%$ del PIB en el 2015. Por otra parte, tampoco se entiende que la LAPAD, tal como estaba estructurada, pudiera perjudicar a los intereses del sector privado cuando todo el sistema de la provisión de servicios del SAAD se efectúa a través de empresas privadas, con algunas excepciones. Ello nos lleva a pensar que la reforma a que se refiere el legislador es la que está relacionada con la PECEF (prestación económica de cuidados en el entorno familiar) cuyo objetivo es sustituir dicha prestación por servicios, dando así una mayor oportunidad de negocio a las empresas privadas. No es baladí que el mayor incremento de prestaciones, en los tres últimos ejercicios, lo hayan experimentado las prestaciones vinculadas, con el agravante de que estos servicios se dan a través de empresas acreditadas que escapan del control de calidad del resto de servicios concertados (públicos).

Tal como señala Rodríguez Cabrero (2014), mediante la crisis, se está profundizando en la privatización de los propios sistemas universales del bienestar. Lo que sitúa lo social en la pura gestión competitiva económica y relega los criterios de acción pública, de primacía de los derechos sobre el presupuesto, además de menoscabar la acción de la iniciativa social, gratuita, sin fin de lucro. Esto ha supuesto que la reestructuración del Estado de bienestar en España en esta última fase de desarrollo haya combinado tanto procesos diferenciados de contención del gasto como de recalibración y privatización (Navarro, 2004; Guillén, 2010; Guillén y León, 2011; Moreno, 2012; Pierson, 2001; Rodríguez Cabrero, 2011a).

El núcleo central de los “recortes” en materia de atención a la dependencia se identifica con el RDL 20/2012 aunque hay una antesala en el RDL $20 / 2011^{13}$ que retrasa el calendario de entrada de los dependientes moderados en un año (hasta 2013), pero es el RDL 20/2012 el que pospone definitivamente su entrada hasta julio del 2015. Asimismo, los Presupuestos Generales del Estado para 2012, 2013 y 2014 han ido aprobando recortes presupuestarios como la suspensión del Nivel Acordado ${ }^{14}$ y la supresión de la bonificación de la cuota de la Seguridad Social del cuidador familiar. El cambio del modelo asistencial se completa con

${ }^{13}$ RDL 20/2011, de 30 de diciembre, de medidas urgentes en materia presupuestaria, tributaria y financiera para la corrección del déficit público.

${ }^{14}$ El Art. 32.3 de la LAPAD define el Nivel Acordado en el marco de la cooperación interadministrativa pudiendo establecer convenios entre la AGE y las Autonomías. 
la Resolución de 13 de julio de $2012^{15}$ que reforma la contribución de los usuarios (copago) elevando sus aportaciones al Sistema. Otras disposiciones posteriores sintetizan el contenido del nuevo modelo asistencial (RD 1051/2013), definen los nuevos criterios de financiación del Nivel Mínimo (RD 1050/2013) y disponen los nuevos criterios de la información de las CC.AA. al Sistema de Información del SAAD, el SISAAD (Orden SSI/2371/2013), el cual exige mayor nivel de información a las CC.AA. sobre el gasto y los ingresos del presupuesto en atención a la dependencia.

El conjunto de medidas que inciden en el ahorro del gasto público se pueden agrupar en tres bloques: un primer grupo lo hacen recortando derechos o exigiendo mayor colaboración de las personas beneficiarias (retraso del derecho de entrada de las personas dependientes de Grado 1, incremento de los copagos, supresión de la bonificación de la cuota de la Seguridad Social); un segundo grupo, conteniendo el gasto mínimo exigido a las autonomías en la gestión de las prestaciones (reducción de la intensidad de las prestaciones, reducción de las cuantías máximas de las prestaciones económicas, carencia de dos años en la prestación económica del cuidador familiar, eliminación de los niveles de dependencia); un tercer grupo, disminuyendo la financiación estatal a las autonomías (disminución de las cuantías del Nivel Mínimo, suspensión del Nivel Acordado) [Montserrat Codorniu, 2014].

A continuación se analiza el impacto en los usuarios de las medidas más relevantes de la refundación de la LAPAD enunciadas en el párrafo anterior.

\section{Medidas que afectan al derecho de entrada en el sistema y a la efectividad de las prestaciones}

La medida más relevante del RDL 20/2012, y que más indefensión ha creado en los usuarios, ha sido la de posponer el derecho de entrada en el Sistema a las personas beneficiarias de Grado 1 (dependencia moderada) durante tres años - de julio 2012 a julio 2015 - sin que éstas puedan reclamar ningún tipo de indemnización. El número de personas afectadas ${ }^{16}$ por dicho retraso se calcula en alrededor de 550 mil.

Los políticos de los recortes presupuestarios no tuvieron en cuenta el estado de fragilidad de las personas en situación de dependencia, ni el impacto en el bienestar de ellas, ni en el de sus familiares.

${ }^{15}$ Resolución de 13 de julio de 2012, de la Secretaría de Estado de Servicios Sociales e Igualdad, por la que se publica el Acuerdo del Consejo Territorial del Sistema para la Autonomía y Atención a la Dependencia para mejora del sistema para la autonomía y atención a la dependencia.

${ }^{16}$ El Libro Blanco de la dependencia cifra el número de personas con dependencia moderada en 648 mil y, actualmente, en el Sistema hay casi 90 mil atendidas.
La Asociación Estatal de Directores y Gerentes de Servicios Sociales (AEDGSS) calcula que durante los últimos cuatro años más de 100.000 personas han fallecido antes de que se les concediera la prestación a la cual ya tenían derecho, sin que el beneficiario, ni los familiares, puedan reclamar nada del retraso en el derecho.

Las familias han sido y continúan siendo el principal soporte de sus familiares cuando necesitan cuidados continuados a pesar de los cambios culturales, de la progresiva incorporación de la mujer al mercado laboral y de la separación de los núcleos familiares entre padres e hijos. En las personas mayores, el cónyuge es el cuidador principal en más de $85 \%$ de los casos y si la persona a cuidar es un hombre, la asistencia es desempeñada por la esposa en casi la mitad de los casos (Martínez Bujan, 2011). Ello dibuja un panorama en que los mismos cuidadores suelen ser personas mayores que, en muchas ocasiones, deberían ser ellas mismas las que recibieran cuidados. Asimismo, cuando las personas en situación de dependencia viven solas, o con sus hijos, suelen ser familiares femeninos (hija, nuera, nieta) quienes se hacen cargo de ellas, sacrificando oportunidades laborales y dedicando una gran cantidad de su tiempo y esfuerzo a cuidarlos (Rodríguez Cabrero, 2004). En general, la carga asistencial de los cuidadores familiares es muy elevada, sobre todo si no reciben ayudas públicas o tienen capacidad económica para contratar servicios profesionales en el mercado privado, lo cual no sucede en la mayor parte de la población. Por ello, los recortes asistenciales aplicados por el Gobierno para contener el déficit publico posponiendo los beneficios de la Ley a las personas con dependencia moderada ha supuesto un "fuerte golpe", tanto a los beneficiarios como a sus familias, que se han visto privados de unos servicios profesionales que hubiesen aliviado su carga de cuidados a sus familiares.

La Tabla 1 muestra las diferencias del número de personas beneficiarias en el Sistema entre las estimaciones del Libro Blanco y la situación en 2014. La LAPAD estimaba que, a principios de 2015, habría 1,3 millones de personas beneficiarias mientras que las cifras muestran que, en 2014 se han atendido 734.690 beneficiarios con prestación, es decir, poco más de la mitad de los usuarios previstos (53,5\%).

\subsection{El limbo de la dependencia y la efectividad de las prestaciones}

Las personas beneficiarias se encuentran indefensas cuando se encuentran en el "limbo de la dependenci ${ }^{17}$ " - periodo de espera entre haberles sido reconocido el derecho a la prestación y la prestación efectiva ${ }^{18}-$. Hay diferentes situaciones

\footnotetext{
${ }_{17}$ Término acuñado por la Asociación Estatal de Directores y Gerentes de Servicios Sociales de España.

${ }^{18}$ En las prestaciones económicas, que se esté cobrando la prestación, y en los servicios, que se estén percibiéndolos.
} 
Tabla 1. Población beneficiaria por grados de dependencia, prevista y actual en el 2014

\begin{tabular}{|c|c|c|c|c|c|}
\hline & $\begin{array}{c}\text { Dependencia } \\
\text { moderada }\end{array}$ & $\begin{array}{l}\text { Dependencia } \\
\text { severa }\end{array}$ & $\begin{array}{c}\text { Gran } \\
\text { dependencia }\end{array}$ & Total & Îndice \\
\hline \multirow{2}{*}{ Libro Blanco } & 648.442 & 472.461 & 252.345 & 1.373 .248 & \multirow{2}{*}{100} \\
\hline & $47,22 \%$ & $34,40 \%$ & $18,38 \%$ & $100,00 \%$ & \\
\hline \multirow{2}{*}{ A 31/12/2014 } & 89.803 & 353.726 & 291.162 & 734.690 & \multirow{2}{*}{$53,50 \%$} \\
\hline & $12,22 \%$ & $48,15 \%$ & $39,63 \%$ & $100,00 \%$ & \\
\hline
\end{tabular}

Fuentes: Libro Blanco, SISAAD y elaboración propia.

Gráfico 1. Evolución de los principales parámetros de gestión de los expedientes: beneficiarios pendientes de recibir prestación

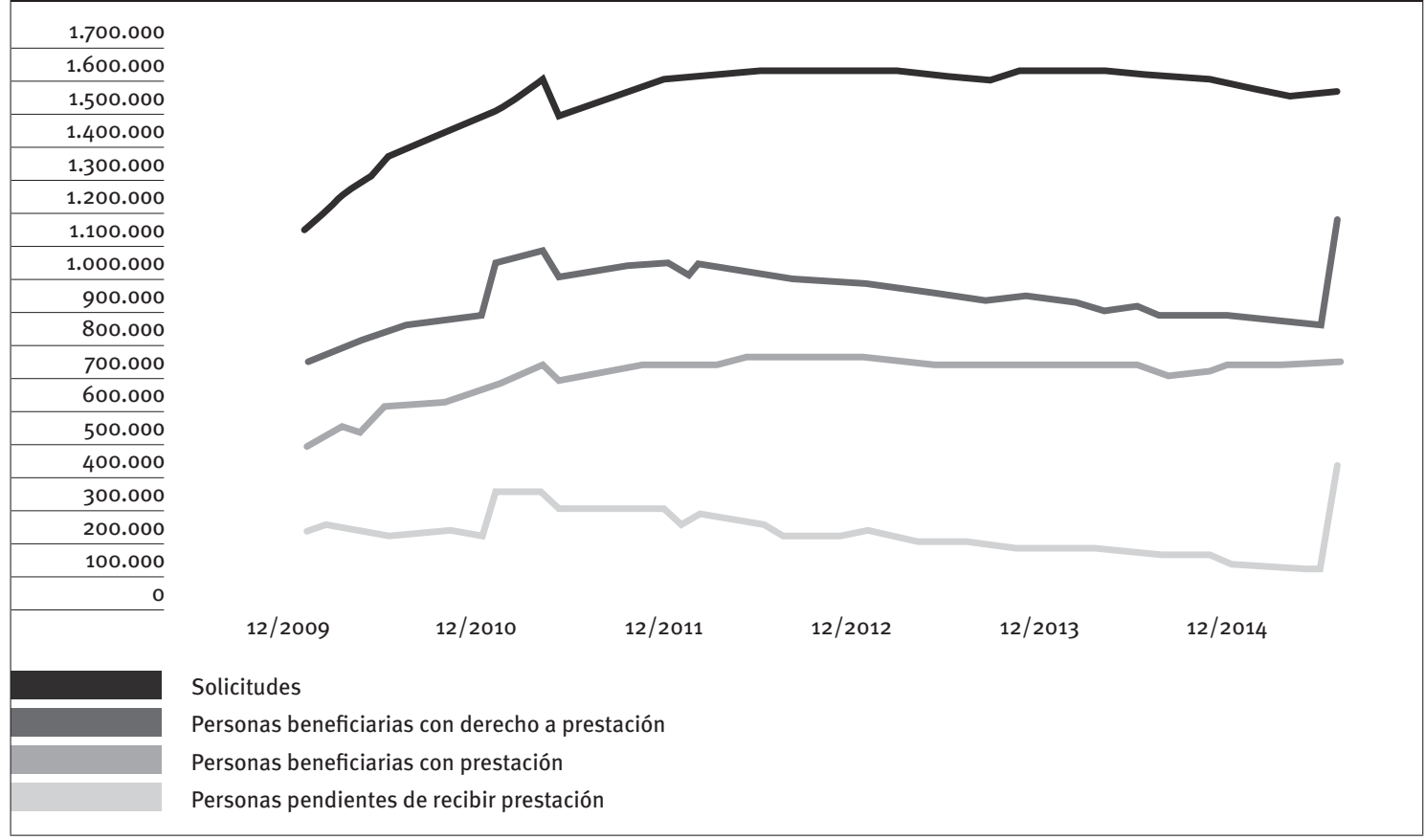

Fuente: SISAAD y elaboración propia.

de las personas que se encuentran en el "limbo", pudiendo distinguir las siguientes: a) aquellas que habiendo sido reconocidas como dependientes están esperando que les hagan el PIA (Plan Individual de Atención); b) aquellas que, aunque tengan el PIA, están en la "lista de espera" para entrar en un servicio y c) aquellas a las que les ha asignado una prestación económica de cuidados en el entorno familiar y están en la "lista de sufridores" porque la Administración, de acuerdo con el RDL 20/2012, puede dejar en "suspenso" la prestación durante un plazo de dos años. El SISAAD no desglosa la tipología de las personas que están en el "limbo", con lo que no se puede conocer cuantas hay en cada grupo.

A partir de la segunda mitad de 2011, el número de personas en el limbo empezó a descender, no tanto por la mayor agilidad en la gestión de los expedientes como por los recortes presupuestarios que han provocado que las autonomías mantengan estable $^{19}$ el nivel de beneficiarios hasta mitad del
2015. A partir de dicha fecha, el limbo ha aumentado en 285.850 personas debido a que han empezado a aflorar las Resoluciones de dependencia con Grado 1.

El Gráfico 1 muestra la evolución global de los principales parámetros de la gestión de los expediente desde enero de 2010, percibiéndose el progresivo aumento de las prestaciones hasta 20112012 para, a partir de entonces, mantener la oferta asistencial constante a pesar de un ligero repunte de solicitudes en el 2013 que apenas se ha visto correspondido con un incremento de prestaciones.

Las CC.AA. afrontan la entrada de los nuevos beneficiarios del Grado 1 en el Sistema con un porcentaje conjunto de personas pendientes de recibir prestación de alrededor del $17 \%$ del total de personas beneficiarias (Gráfico 2). El punto de partida no es igual en todas las CC.AA.; las cinco que se encuentran por encima de la media son Murcia, Aragón, Galicia, Andalucía y Valencia.

19 Durante dicho periodo, generalmente, la entrada de nuevos beneficiarios solo se realizaba si había bajas en el Sistema. 


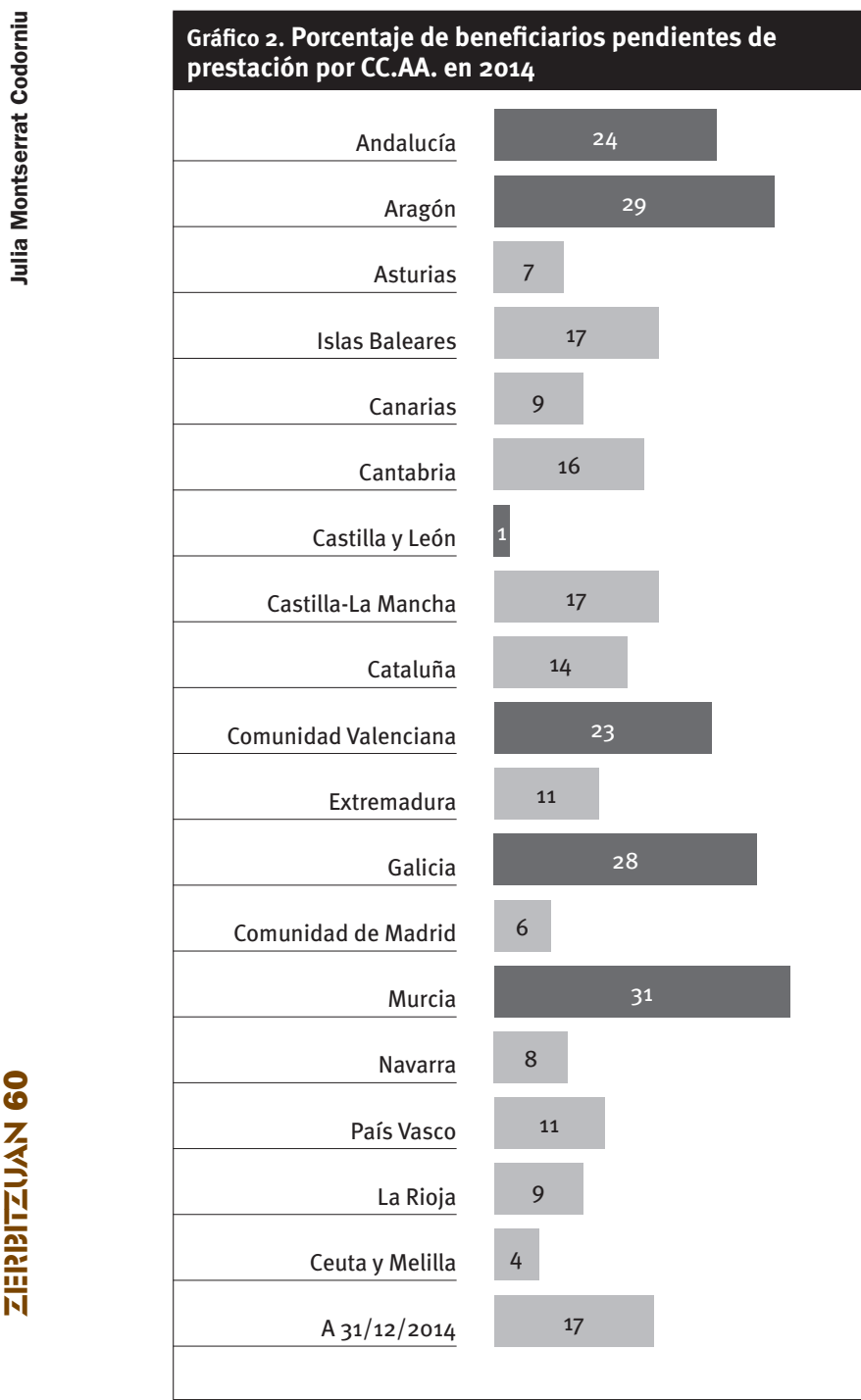

Fuente: SISAAD y elaboración propia.

\subsection{Las medidas de desincentivación de la prestación económica de cuidados en el entorno familiar}

Otra de las medidas que afectan directamente a los derechos de las personas beneficiarias es la de no hacer efectiva la prestación económica de cuidados en el entorno familiar (PECEF). El RDL 20/2012 concede a la Administración autonómica la potestad de no pagar la PECEF durante un plazo de dos años sin que el afectado pueda reclamar los atrasos. Esta disposición no obliga a las Administraciones autonómicas a aplicarla, pero la mayoría de ellas la utilizan bajo el pretexto de los recortes presupuestarios. Ello provoca un importante efecto desincentivador de la demanda de dicha prestación, a la cual se añaden los recortes en las cuantías “máximas" de la PECEF.

Es sorprendente ver como la actitud de la Administración en el tratamiento de la PECEF ha cambiado sustancialmente en los ocho años de vida de ésta. Al principio, la persona beneficiaria tenía derecho a reclamar los atrasos (retroactividad) desde la presentación de la solicitud de la dependencia; a partir de junio de 2010, solo se reconocen atrasos si transcurren más de seis meses desde la solicitud hasta la resolución del PIA y, a partir de julio 2012, se “congela" la efectividad de la prestación durante dos años (periodo máximo) sin que genere el derecho a recibir los atrasos. La situación actual constituye un atropello a los derechos de las personas que se ven privadas de una prestación concedida por su propia Administración.

Las nuevas cuantías de la PECEF, a partir de la segunda mitad de 2012 , disminuyen un $15 \%$ respecto a las establecidas en el 2011 y los importes para los nuevos beneficiarios se sitúan en el abanico de los dos niveles de dependencia existentes previamente para cada uno de los grados; así, las nuevas cuantías son: $387,6 € /$ mes para atender a una persona con dependencia muy grave (Grado 3); $268,79 € /$ mes si el beneficiario tiene una dependencia severa (Grado 2) y para los del Grado 1 es de $153 € /$ mes. Si a la rebaja de las prestaciones añadimos que el cuidador se deberá costear la cuota de la Seguridad Social (opcional), el resultado es de un importe neto de $223 € /$ mes (Grado 3), de 104,25 $€ /$ mes (Grado 2) o de $70,73 € / m e s$ (Grado 1). Además, a dichos importes se les deberá deducir el copago correspondiente en función de la capacidad económica de la persona, con lo que los nuevos importes de la PECEF son "simbólicos".

Las medidas descritas en los dos párrafos anteriores forman parte de los objetivos del Gobierno de "acoso y derribo de la PECEF" que, atendiendo al principio de “excepcionalidad" del artículo 14.4 de la LAPAD, promueve la prestación de cuidados formales a través de empresas privadas, que frecuentemente no forman parte de la red pública de servicios, utilizando la fórmula de "prestaciones vinculadas al servicio".

\subsubsection{Evolución del número de PECEF}

Hasta 2012, la PECEF era la prestación “estrella” en todas las CC.AA., llegando a alcanzar porcentajes superiores al $50 \%$ en algunas de ellas. Es a partir del RDL 20/2012 y del Acuerdo del Consejo Territorial de 10/7/2012 que se inicia el camino de su desmantelamiento mediante las medidas descritas anteriormente, añadiendo, además, otra medida que afecta directamente a las finanzas autonómicas y que consiste en utilizar el Nivel Mínimo de financiación para penalizar ${ }^{20}$ a aquellas CC.AA. que continúen teniendo una proporción elevada de PECEF.

${ }^{20}$ Se aplica un coeficiente corrector a la parte variable del Nivel Mínimo (porcentaje del total a repartir) de forma que aquellas CC.AA. cuya proporción de PECEF respecto al total de prestaciones sea superior a la media del conjunto de las CC.AA., recibe un importe inferior al que le correspondería, y viceversa. 
Gráfico 3. Proporción de la prestación de cuidadores familiares sobre el total de prestaciones por CC.AA.

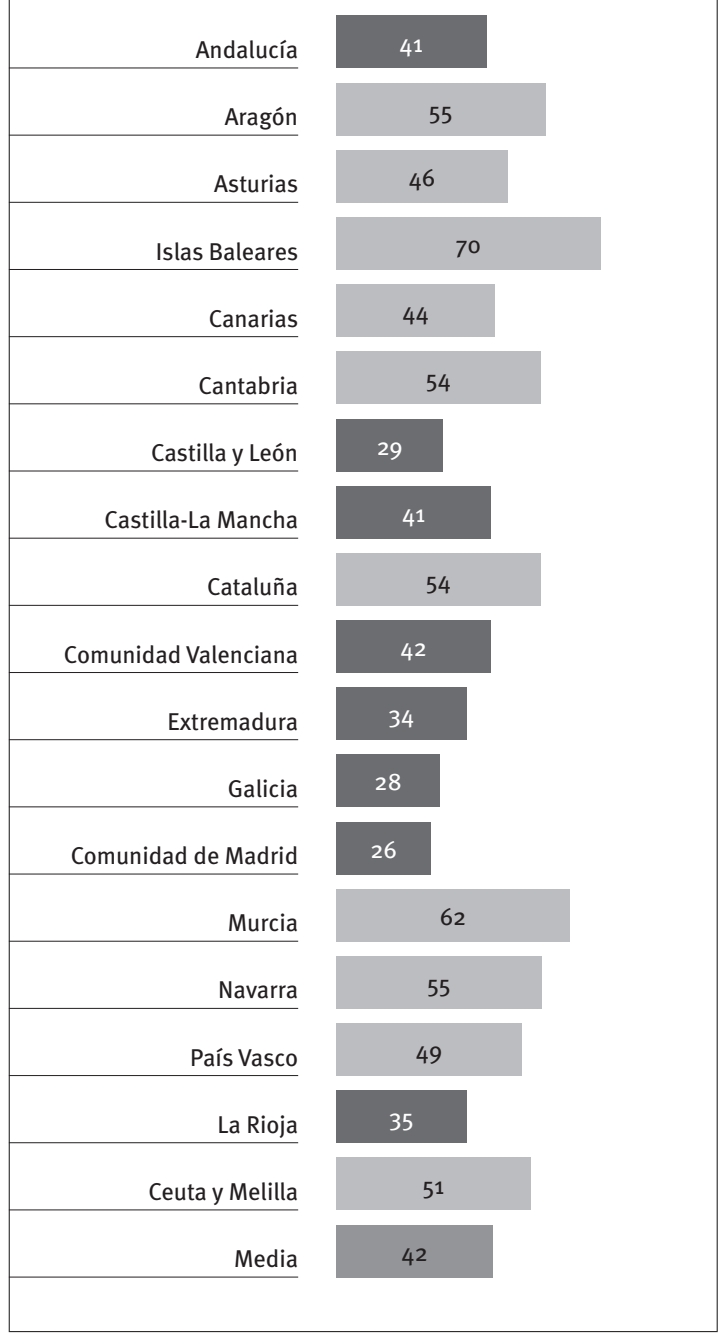

Fuente: SISAAD y elaboración propia.

La PECEF ha sido la prestación estrella porque los políticos la han utilizado como recurso "fácil", "propagandístico" y "barato". Probablemente, el tema económico tiene mucho peso en su proliferación pero no es menos cierto que existe un trasfondo político en su uso masivo ya que, al ser un recurso fácil de conceder, la administración autonómica justificaba su contribución al despliegue del SAAD aumentando de manera rápida el número de beneficiarios con prestación. Todavía en el 2014, a pesar de todos los recortes y restricciones en su concesión, hay once CC.AA. en las que dicha prestación representa el porcentaje mayor sobre el total de las prestaciones. La media del porcentaje de PECEF en el conjunto de las CC.AA. es del $42 \%$ siendo las CC.AA. con valores extremos, la de Baleares con el $70 \%$ y la C.A. de Madrid con el $26 \%$ (Gráfico 3).

La evolución entre 2010 y los dos últimos ejercicios muestra el descenso generalizado de la PECEF y el diferente comportamiento de las CC.AA (Tabla 2). El porcentaje de la PECEF era, en 2010, del $49 \%$, en
2013 del $44 \%$ y en 2014 del $42 \%$; es decir, entre 2010 y 2014 ha bajado siete puntos porcentuales. El cambio de tendencia se nota en la mayoría de las CC.AA., especialmente entre 2013 y 2014, primer ejercicio en el que se ha aplicado la penalización de su uso masivo a través del Nivel Mínimo de financiación. No obstante, hay CC.AA. que no siguen la tendencia general como es la C.A. de Madrid que muestra crecimientos en cada uno de los periodos y la C.A. de Baleares que se mantiene prácticamente constante en los tres años analizados; por otro lado, País Vasco y Navarra aumentan considerablemente el peso de la PECEF entre 2010 y 2013, y bajan ligeramente entre 2013 y 2014 continuando por encima de la media global.

Tabla 2. Evolución del porcentaje de la prestación económica de los cuidados en el entorno familiar sobre el total de prestaciones. 2010, 2013 y 2014

\begin{tabular}{|l|c|c|c|}
\hline CCAA & 2010 & $\mathbf{2 0 1 3}$ & $\mathbf{2 0 1 4}$ \\
\hline ANDALUCIA & 45,45 & 41,34 & 40,59 \\
\hline ARAGON & 63,48 & 60,30 & 54,55 \\
\hline ASTURIAS & 47,72 & 47,30 & 45,58 \\
\hline
\end{tabular}

\begin{tabular}{|l|c|c|c|}
\hline COMUNIDAD VALENCIANA & 46,18 & 43,14 & 41,94 \\
\hline EXTREMADURA & 42,62 & 39,64 & 34,30 \\
\hline GALICIA & 58,19 & 30,24 & 28,00 \\
\hline COMUNIDAD DE MADRID & 18,42 & 22,47 & 26,33 \\
\hline MURCIA & 75,78 & 63,35 & 62,30 \\
\hline NAVARRA & 62,49 & 56,20 & 54,61 \\
\hline PAIS VASCO & 42,84 & 50,19 & 48,74 \\
\hline LA RIOJA & 46,23 & 37,34 & 34,65 \\
\hline CEUTA MELILLA & 64,33 & 51,60 & 51,23 \\
\hline TOTAL (\%) & 49 & 44 & 42 \\
\hline Promedio prestaciones año & 334.241 & 410.424 & 389.961 \\
\hline
\end{tabular}

Fuente: SISAAD y elaboración propia.

\subsection{La incoherencia de la desincentivación de la PECEF}

El legislador de la LAPAD diseñó un Sistema de atención a la dependencia altamente profesionalizado pensando más en la creación de empleo que en configurar un sistema de prestaciones que satisfaga la opción de los usuarios de ser cuidados por familiares y permanecer en su domicilio, siendo, además, la opción preferida por la mayoría de las personas según las encuestas. 
Se argumenta que la atención prestada por cuidadores formales es de más calidad que la realizada por cuidadores informales (familiares) porque el dinero que recibe el familiar no se aplica a cuidar mejor a su "pariente" (más horas de dedicación, mejoras en su alimentación y/o higiene, sacarlo a pasear, etc.). Si bien dicha afirmación puede ser cierta en algunos casos, no se dispone de evidencia empírica que lo demuestre. En todo caso, el problema deriva del diseño de la "prestación", que no define correctamente la finalidad y el empleo de la misma.

Si el objetivo es mejorar la calidad del cuidado que recibe la persona, sorprende que el servicio "sustitutivo" más idóneo -servicio de ayuda domiciliaria (SAD) - se preste con solo una hora y media de trabajador/a familiar ${ }^{21}$ cuando se supone que una persona en situación de dependencia grave (Grado 2) y muy grave (Grado 3 ) requiere cuidados continuados dos o tres veces al día, según la propia definición que da la Ley 39/2006. Con una prestación de tan baja intensidad es difícil pensar que el SAD esté siendo un servicio "sustitutivo" efectivo, y de calidad, de la prestación de cuidados familiares.

Se observa que otros países de la UE (Austria, Holanda; Noruega conceden, también, prestaciones monetarias a beneficiarios de prestaciones públicas de atención a la dependencia, pero tanto el nombre de la prestación - presupuesto personal- como su finalidad son radicalmente diferentes a los de la PECEF. El objetivo del "presupuesto personal" no es compensar al cuidador por su coste de oportunidad de cuidar al "pariente", sino que el destinatario de la prestación es la propia persona beneficiaria, siendo ella la responsable de su gasto (compra de servicios formales e informales, productos de higiene, productos alimenticios, ocio, etc.). Asimismo, el gestor del caso supervisa la correcta aplicación de la prestación según los criterios de gasto consensuados entre el usuario y la Administración. Junto al "presupuesto personal" se prevé una serie de "servicios complementarios" como, por ejemplo, formación tanto para el usuario como para el cuidador, servicios de respiro, asesoramiento, uso de nuevas tecnologías, entre otros.

Se está haciendo fracasar una prestación económica que otros países de la UE están promoviendo. La propia Comisión Europea prevé que, en el transcurso de los próximos cincuenta años, la conjunción de factores como el aumento del envejecimiento, la escasez de población activa, junto con el previsible incremento de los precios de los servicios formales, harán necesario redefinir el apoyo y la asistencia de los cuidadores familiares. En definitiva, se debería repensar una nueva PECEF que tuviese como objetivo

${ }^{21}$ La nueva regulación de 2012 establece que una persona con dependencia muy grave reciba, como promedio, entre 1,5 y 2,3 horas al día; una persona con dependencia severa, entre 1,5 horas y $40 \mathrm{mi}-$ nutos al día, y aquellas con dependencia leve podrán recibir un máximo de 40 minutos al día. el "empoderamiento" del usuario para la elección y gestión de los recursos necesarios para permanecer en su domicilio reforzando aquellos servicios complementarios necesarios para cuidar, tanto a la persona beneficiaria como al cuidador. Por ello sería conveniente "despenalizar" la PECEF y restituir la prestación a los niveles previos al ejercicio 2012 en tanto no se defina la "nueva PECEF".

\subsection{Supresión de la bonificación de la cuota de la Seguridad Social al cuidador familiar}

La supresión de la bonificación de la cuota de la Seguridad Social al cuidador familiar forma parte del paquete de medidas de "acoso y derribo" de la prestación económica de cuidados en el entorno familiar. Aunque dicha medida no afecta directamente a la persona beneficiaria, en cambio afecta a la calidad asistencial ya que el cuidador podía disponer de los beneficios de la asistencia sanitaria (en caso que no los tuviese) y no perder tiempo de cotización a la Seguridad Social para el reconocimiento de su futura pensión de jubilación ${ }^{22}$. En caso contrario, la cuidadora (generalmente son mujeres) podría verse obligada a mantener su puesto de trabajo para no perder ese derecho, lo cual incide en una disminución de horas de presencia física de cuidados y aumento del estrés al tener que compatibilizar el cuidado de la familia con el cuidado del familiar dependiente y con el empleo fuera del domicilio. Esta medida ha afectado, disminuyéndolo en más de 150.000, al número de altas en la Seguridad Social por este concepto, pasando de 179.829 en julio de 2012 a 11.957 en julio de 2015.

\section{La oferta y la calidad asistencial de las prestaciones de la LAPAD}

El Real Decreto 1051/2013, de 27 de diciembre, por el que se regulan las prestaciones establecidas en la LAPAD, ordena el nuevo contexto asistencial nacido de la refundación de la LAPAD. La principal característica de la reforma es la reducción de las intensidades, lo que conlleva, indirectamente, la reducción de la calidad asistencial.

Las intensidades de las prestaciones se definen desde la perspectiva de la utilización del servicio, o sea, por el número de horas que la persona beneficiaria tiene el derecho a utilizarlo. Sin embargo, no hace mención alguna de los servicios residenciales porque se da por supuesto que la persona beneficiaria los utiliza durante las 24 horas al día; no obstante, el mantenimiento, 0 rebaja en algunos casos, de los costes en los centros (residencias, centros de día) se da en la "no exigencia estricta de la calidad mínima" asistencial que deberían tener estos centros.

\footnotetext{
${ }^{22}$ Ello solo afecta a los cuidadores "jóvenes”, es decir con eda-
} des inferiores a la edad legal de jubilación. 
La reducción de las intensidades de utilización de los servicios según el RDL 20/2012 es importante, tal como se observa en la efectuada en los servicios de ayuda a domicilio (Tabla 3). La comparativa entre el número de horas de atención antes y después de la reforma muestra rebajas sustanciales. Así, el tope máximo de horas mensuales para las personas con dependencia Grado 3, baja de 90 a 70 horas; para las personas con dependencia Grado 2, el tope desciende de 55 a 45 horas y en las personas con dependencia leve, el tope pasa de 30 a 20 horas. De todas formas, el impacto real de la reforma se manifestará cuando se analice el número de horas efectivamente prescritas a los beneficiarios, ya que hay un amplio abanico de posibilidades en cada uno de los tramos de dependencia, pudiendo ocurrir que la mayoría de las prescripciones se hagan por el mínimo. Se debería reivindicar que el SISAAD recogiera el número de horas de ayuda a domicilio prestadas además del número de beneficiarios.

Tabla 3. Número máximo de horas de utilización de los servicios de ayuda a domicilio antes y después de los recortes

\begin{tabular}{|c|c|c|c|}
\hline & \multicolumn{2}{|c|}{ Reforma Ley 20/2012 } \\
\hline $\begin{array}{l}\text { Grados } \\
\text { dependencia }\end{array}$ & LAPAD & $\begin{array}{c}\text { Beneficiarios } \\
\text { antes } \\
\text { Agosto } 2012\end{array}$ & $\begin{array}{c}\text { Beneficiarios } \\
\text { después } \\
\text { Agosto } 2012\end{array}$ \\
\hline Grado 3-2 & $\begin{array}{l}\text { Entre } 70 \mathrm{y} \\
90 \mathrm{~h} / \mathrm{mes}\end{array}$ & $\begin{array}{c}\text { Entre } 56 \text { y } 70 \\
\text { h/mes }\end{array}$ & \multirow{2}{*}{$\begin{array}{c}\text { Entre } 46 \text { y } 70 \\
\mathrm{~h} / \mathrm{mes}\end{array}$} \\
\hline Grado 3-1 & $\begin{array}{l}\text { Entre } 55 \mathrm{y} \\
70 \mathrm{~h} / \mathrm{mes}\end{array}$ & $\begin{array}{c}\text { Entre } 45 \text { y } 55 \\
\text { h/mes }\end{array}$ & \\
\hline Grado 2-2 & $\begin{array}{l}\text { Entre } 40 \text { y } \\
55 \mathrm{~h} / \mathrm{mes}\end{array}$ & $\begin{array}{c}\text { Entre } 31 \text { y } 45 \\
\text { h/mes }\end{array}$ & \multirow{2}{*}{$\begin{array}{c}\text { Entre } 21 \text { y } 45 \\
\mathrm{~h} / \mathrm{mes}\end{array}$} \\
\hline Grado 2-1 & $\begin{array}{l}\text { Entre } 30 \mathrm{y} \\
40 \mathrm{~h} / \mathrm{mes}\end{array}$ & $\begin{array}{c}\text { Entre } 21 \text { y } 30 \\
\text { h/mes }\end{array}$ & \\
\hline Grado 1-2 & $\begin{array}{l}\text { Entre } 21 \mathrm{y} \\
30 \mathrm{~h} / \mathrm{mes}\end{array}$ & \multirow{2}{*}{$\begin{array}{l}\text { Maximo } 20 \\
\text { horas /mes }\end{array}$} & \multirow{2}{*}{$\begin{array}{l}\text { Maximo } 20 \\
\text { horas /mes }\end{array}$} \\
\hline Grado 1-1 & $\begin{array}{l}\text { Entre } 12 \mathrm{y} \\
20 \mathrm{~h} / \mathrm{mes}\end{array}$ & & \\
\hline
\end{tabular}

Fuente: Ley 20/2012 y elaboración propia.

En los centros de día y en los servicios de promoción, mantenimiento y recuperación de la autonomía funcional, también se limita el número de horas de utilización, si bien la norma hace referencia a los mínimos de atención. Así, establece con carácter general 15 horas mensuales de atención para las personas con dependencia de Grado 1, si bien en los servicios de atención temprana hace referencia a seis horas mensuales (según anexos I, II y III del RD 1051/2013).

\subsection{La mercantilización de la oferta y la calidad asistencial de las prestaciones}

La red pública del SAAD se compone de un conjunto de centros, algunos pocos de titularidad pública y otros muchos de titularidad privada. Los políticos que configuraron la LAPAD dejaron clara la voluntad de aprovechar al máximo los recursos existentes en el mercado y evitar duplicidades. La Administración ofrecería los servicios a través de empresas privadas (con o sin fin de lucro) con las que concertaría un número determinado de plazas o servicios, estableciendo un precio de compra y exigiendo una cierta garantía de calidad en los mismos. El proceso y los requisitos de concertación siguen las normas y procedimientos de los concursos públicos según lo dispuesto en la Ley de Contratos del Estado.

La mercantilización de la prestación de servicios de atención a la dependencia requiere que la Administración pública establezca una serie de requisitos y estándares de calidad para controlar su funcionamiento. Así, el artículo 35.1 de la LAPAD manda que se acuerden estándares esenciales de calidad para cada uno de los servicios que conforman el catálogo de prestaciones de la Ley, previo acuerdo del Consejo Territorial del Sistema para la Autonomía y Atención a la Dependencia.

El acuerdo del Consejo Territorial del SAAD de 27 de

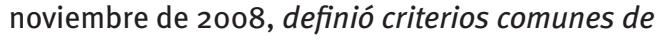
acreditación para garantizar la calidad de los centros y servicios del SAAD haciendo referencia a ratios de plantilla mínimos según los distintos tipos de centro $^{23}$; ratios de atención directa mínimos exigibles para la categoría profesional de cuidador, gerocultor o similar atendiendo a los distintos tipos de centro; definición de la cualificación que deben tener los trabajadores y estableció el requisito de que al menos el $35 \%$ de las plantillas de los centros residenciales debían encontrarse debidamente cualificadas en 2011 y el $100 \%$ en 2015.

En la práctica, apenas la mitad de las autonomías han transpuesto los criterios de acreditación a sus respectivas normas autonómicas (Martín Serrano, 2014). Y, aún más, debido a los recortes presupuestarios derivados de la crisis económica, se deduce la existencia de un "pacto oculto" entre Administraciones y empresas, en el sentido de que la contraprestación a no incrementar (o incluso reducir) los costes de las plazas concertadas es que la Administración no entre a fondo en la exigencia de los ratios de personal y de cualificación profesional definidos en el Acuerdo del Consejo Territorial del 2008. Las empresas y entidades se amparan en la no existencia de la norma autonómica correspondiente que obligue a su cumplimiento.

La calidad en los servicios de atención a la dependencia se resiente aún más cuando contemplamos que hay grietas por donde se escapa cualquier atisbo de control de calidad por parte de la Administración. Éstas son las empresas privadas que ofrecen cualquier tipo de servicios del catálogo de prestaciones a las personas, beneficiarias de la Ley, que obtienen una "prestación vinculada”. El único objeto de control administrativo es el de exigir el cumplimiento de los requisitos para abrir el centro

${ }^{23}$ Diferencia los centros para mayores de los centros para personas con disminución física, psíquica y sensorial menores de 65 años. 
y el de establecer un "precio preferencial" a los usuarios de la LAPAD; son los requerimientos para obtener el certificado de "acreditadas". La relación contractual se establece entre usuario y empresa y, por lo tanto, será el usuario y no la Administración quien pueda exigirle explicaciones sobre la calidad del servicio. Por ello, diferentes instituciones, entre ellas el Observatorio de la Dependencia, solicitan a la Administración que exija a las empresas acreditadas los mismos estándares de calidad que en las empresas concertadas.

Otra de las causas que resienten la calidad asistencial es la de no hacer cumplir los mínimos de plantilla con la debida cualificación profesional. A nivel global, esto se traduce en unos resultados que no son los que se habían pactado. Se estima un déficit que supera la cifra de 18.000 que reconocía el IMSERSO en abril de 2014 (Martín Serrano, 2014). Las administraciones autonómicas argumentan falta de recursos económicos para la oferta de formación profesional; ello hace tambalear el binomio de "calidad en el empleo = calidad asistencial".

Otra característica de la baja calidad asistencial es la de la precariedad de los empleos, que se traduce en remuneraciones bajas, elevada proporción de contratos temporales y de tiempo parcial, dando lugar a una elevada rotación de personal en los centros que afecta a la calidad de los servicios.

El empleo generado, entre 2007 y 2014, apenas alcanza 60 mil puestos según datos de afiliación a la Seguridad Social ${ }^{24}$, pasando de 299.596 en 2007 a 357.169 en 2014 , incremento que está muy alejado del que menciona el Libro Blanco de dependencia y Sosvilla-Rivero (2012), los cuales preveían que se alcanzarían cifras de empleo de alrededor de 600.000 puestos de trabajo. La falta de creación de empleo afecta mayoritariamente a las mujeres ya que es un sector muy feminizado. Entre las causas del escaso crecimiento del empleo están, por un lado, la falta de exigencia administrativa de que los centros cumplan con los ratios de personal mínimos requeridos según el Acuerdo Territorial y, por otro, la reducción de las intensidades de prestación que introdujo el RDL 20/2012 y que se detallan en el Real Decreto 1051/2013.

Finalmente, la "creación de empleo" en empresas privadas fuera del control de la Administración pública, como sucede con las prestaciones vinculadas, dificulta valorar cuantitativa y cualitativamente su efecto.

${ }^{24}$ Portal de la dependencia. Evolución anual afiliación de la Seguridad Social de profesionales de servicios sociales por sectores de actividad.

\section{La financiación de la dependencia}

La LAPAD establece un modelo mixto de financiación público-privado y la colaboración entre los diferentes niveles de Administración en la cobertura del gasto en atención a la dependencia (artículos 7 y 9 de la LAPAD). Los usuarios deben contribuir a la financiación del coste de las prestaciones mediante los $\operatorname{copagos}^{25}$, lo cual no es ninguna novedad ya que en el modelo asistencial anterior a la LAPAD ya se venía realizando. La colaboración entre las AAPP en la financiación del coste del Sistema es un concepto indefinido arrastrando problemas sobre "la medición de la colaboración”. El modelo actual de financiación comporta desajustes en la distribución de la carga financiera entre la Administración general del Estado y las Administraciones autonómica e inequidades en la carga económica que soportan los usuarios.

\subsection{La contribución de los usuarios en la financiación de la dependencia}

La corresponsabilidad de los usuarios y la justicia distributiva son los principios que alega la LAPAD para justificar la contribución de los usuarios en la financiación de las prestaciones de la dependencia; no obstante, hay otra razón "no explicita" que es la de recaudar con el objetivo de rebajar el gasto público, de forma que el "gasto neto" ${ }^{26}$ sea menor. La LAPAD estableció que la financiación de una parte del coste de las prestaciones se realizaría a través de la participación de los usuarios (art. 33). Si bien la Ley no mencionó en qué proporción los usuarios contribuirían en la financiación, la Memoria económica estimaba que, en conjunto, el copago compensaría un tercio del coste total.

El copago es uno de los factores de contención de la entrada al Sistema y de expulsión "voluntaria" en otros casos. El copago es "caro" para muchos usuarios, especialmente para las personas mayores que tienen como único ingreso sustantivo una pensión de la Seguridad Social y, como patrimonio, su vivienda habitual. La reducida cuantía del tramo de renta exenta en los servicios no residenciales ( 1 IPREM), la "irrisoria” cuantía de renta garantizada en el servicio residencial (19\% IPREM) ${ }^{27}$, la amenaza de quedarse sin el patrimonio cuando los ingresos líquidos son insuficientes para cubrir la cuota y las cuotas excesivas, entre otras causas, promueven la expulsión de personas beneficiarias del Sistema agravándose en situaciones de pobreza familiar.

El objetivo de maximizar la recaudación a través de los copagos persiste y se potencia, tal como se desprende de los objetivos de la $\angle A P A D$ refundada y del Programa Nacional de Reformas de 2013

\footnotetext{
${ }^{25}$ Algunos autores llaman al copago "repago", ya que las personas beneficiarias ya han pagado sus impuestos.

${ }^{26}$ Generalmente, al hablar de gasto público se hace referencia al gasto total (bruto) y no al que realmente representa el gasto real para las arcas de las finanzas públicas (neto).

${ }^{27}$ Equivale a 118 euros al mes, si se cuenta el IPREM por 14 pagas.
} 


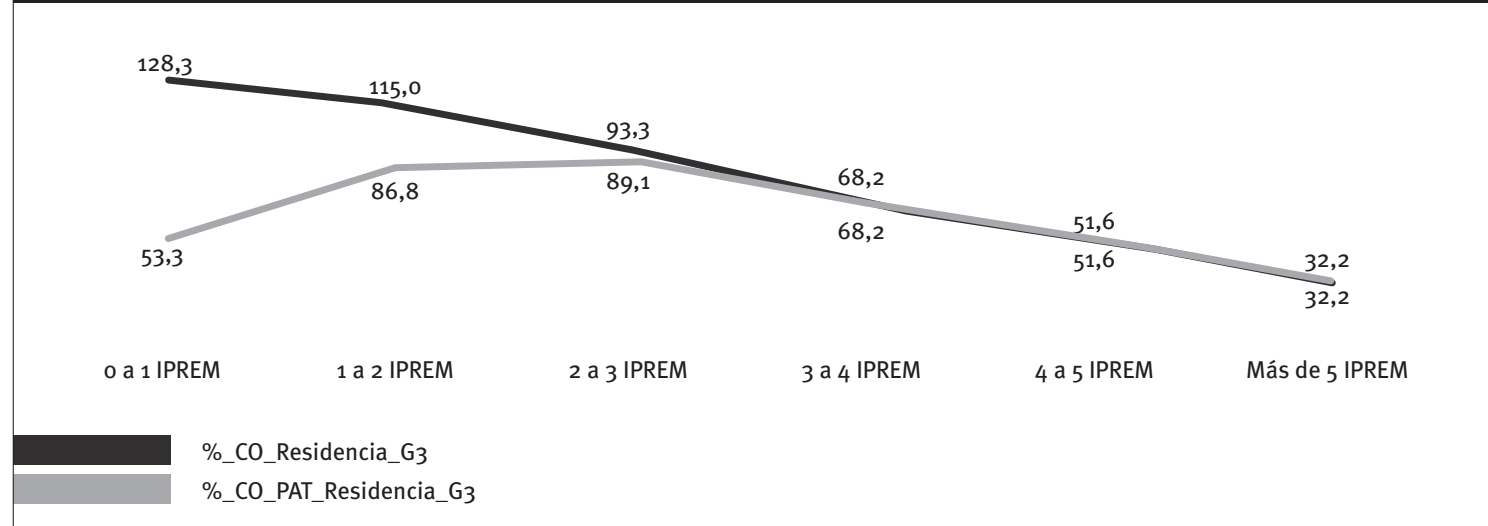

Fuente: Muestra IRPF del IEF-AEAT y elaboración propia.

que preveía un incremento de la recaudación vía copagos del $5 \%$ de los mismos. Teniendo en cuenta el "oscurantismo" del SAAD en proporcionar la información sobre el volumen de copagos "real" y con el objetivo de tener alguna aproximación de la cifra que, actualmente, puede representar, se ha realizado una simulación con una muestra de personas con rentas inferiores a 3 veces el IPREM aplicando los parámetros definidos en la Resolución de 13/7/2012. El resultado de la simulación muestra una cifra de recuperación del coste de las prestaciones, a través de los copagos, alrededor del $23 \%$; otros autores lo estiman, alrededor del $19 \%$ (AEDGSS) y del 27,8\% (Prada, 2014).

La equidad de los copagos no se cumple ni a nivel horizontal (entre los usuarios), ni a nivel vertical (entre las CC.AA.). Las desigualdades entre los individuos surgen porque el Modelo ejerce mayor presión sobre las rentas medias-bajas que sobre las rentas altas, ello significa que una persona con renta baja paga una mayor proporción de renta que otra persona con renta media-alta. También, la filosofía de establecer "tarifas planas" ${ }^{28}$, en lugar de contemplar una escala progresiva de tarifas, así como el hecho de establecer "topes en la cuota" 29 , en lugar de "topes en la renta”, no hace más que agravar la regresividad del modelo. La cuota "topada" por arriba favorece a las rentas media-altas ya que no pagaran más del $90 \%$ del precio del servicio $y$, en definitiva, obtienen un ahorro en el copago proporcionalmente mayor que aquellos que no alcanzan a disfrutar de "ese descuento" en el precio porque su copago no llega al límite.

La inequidad en el copago se acentúa aún más con la inclusión del patrimonio (Montserrat Codorniu y Montejo, 2012). Su imputación eleva el cómputo de la capacidad económica del usuario pero no tiene

\footnotetext{
${ }^{28}$ La tarifa plana establece un precio fijo y aplica una bonificación
} en la cuota a aquellos que no pueden pagarla en su totalidad.

${ }^{29}$ La Resolución de 13/7/2012 la establece en el 90\% del precio del servicio. efectos en la capacidad económica de las rentas altas. Ello es debido a que, a partir de un cierto nivel de ingresos, la persona ya llega al "tope" de lo que debe pagar y, por lo tanto, por más que aumente la capacidad económica, no aumenta la cuota. En cambio, a las personas con rentas mediasbajas, la inclusión del patrimonio eleva su copago hasta el punto de hacerles contraer "deuda con la Administración" ${ }^{30}$ si los recursos líquidos no son suficientes para pagar la cuota resultante. Ello puede provocar la exclusión voluntaria del Sistema de las personas afectadas, produciéndose una pérdida del bienestar de las mismas.

El Gráfico 4 muestra que el modelo de copago actual puede hacer pagar al usuario de renta media-baja entre el $80 \%$ y el $90 \%$ de su renta y si tuvieses patrimonio, la cuota podría llegar a ser superior al importe de sus recursos líquidos, contrayendo en este caso una deuda con la Administración. El "sacrificio económico" que realizan las personas con rentas medias-bajas es superior al de las rentas medias-altas. La línea azul dibuja la evolución del impacto sin tener en cuenta el patrimonio y la línea roja teniéndolo en cuenta. Como se puede apreciar, a partir de una determinada renta, en este caso igual a tres veces el IPREM, el impacto es el mismo "con" o "sin" patrimonio. Es decir, el patrimonio no incrementa el copago de las personas con rentas medias-altas siendo dicho resultado contrario al objetivo establecido.

\subsection{La contribución de la AGE en la financiación del SAAD}

Con anterioridad a la entrada en vigor de la Ley 39/2006, las necesidades de las personas afectadas por estas situaciones eran atendidas, desde los ámbitos autonómico y local, a través de un sistema

${ }^{30}$ Las deudas contraídas figuran como cargas en el Registro de la Propiedad. 
de subvenciones, limitando la entrada al Sistema a aquellas personas situadas por encima de un determinado umbral económico establecido por cada Administración. A partir de la LAPAD, el Estado garantiza la cobertura universal y su financiación estableciendo su colaboración financiera a través del Nivel Mínimo de protección garantizada, comprometiendo a las autonomías a que contribuyan como mínimo con la misma cantidad que la aportada por la Administración General del Estado (art. 32 de la LAPAD) ${ }^{31}$. Inicialmente también se estableció un fondo adicional, llamado Nivel Acordado ${ }^{32}$, cuya finalidad era complementar los recursos del Nivel Mínimo, el cual fue suspendido a partir del ejercicio 2012.

La financiación del Nivel Mínimo se define como la cuantía mínima garantizada por el Estado que la persona beneficiaria tiene derecho a percibir, aunque el usuario no es el receptor directo sino a través de la prestación o prestaciones que le asigna su Administración autonómica. La determinación de las cuantías del Nivel Mínimo la establece anualmente el Gobierno y el gasto anual previsto para financiar los importes devengados durante el ejercicio debe figurar en los correspondientes Presupuestos del Estado (art. 32.1). Al ser una financiación garantizada, el Estado deberá recurrir a los suplementos de crédito en el caso que el presupuesto inicial resultase insuficiente para hacer frente a los derechos devengados durante el ejercicio.

Existe un gran "controversia” entre las autonomías y la AGE sobre la cantidad aportada por el Estado en concepto de Nivel Mínimo. Las primeras sostienen que dicha financiación apenas cubre el $20 \%$ del coste total de las prestaciones y, sin embargo, el IMSERSO argumenta que ha añadido recursos adicionales a través de la Ley $22 / 2009^{33}$ por un importe de 9.268,66 M€ (una media anual de 1.853,73 M€) en el periodo 2009-2013, lo cual haría que la suma de las dos aportaciones alcanzase, aproximadamente, la mitad del coste de las prestaciones, cumpliendo con lo establecido en el art.32 de la LAPAD. Según los datos suministrados al Tribunal de Cuentas ${ }^{34}$, y teniendo en cuenta los recursos adicionales, la AGE, en el 2012, hubiera aportado el 49,23\% del coste de las prestaciones. Sin embargo, los argumentos en contra de tener en consideración dichos recursos son, que la financiación adicional, al ser una financiación incondicionada, no está garantizado que las autonomías la apliquen a los presupuestos de atención a la dependencia, y, además, que no es

${ }^{31} \mathrm{El}$ artículo 32, apartado tercero de la Ley dice que las CC.AA. deben contribuir, como mínimo, con una cantidad de recursos igual a la aportada por la AGE.

${ }^{32}$ Se establecían convenios con las administraciones autonómicas, en los que se establecían los objetivos a cubrir y se repartían los fondos a través de unos criterios definidos y aprobados en el seno del Consejo territorial.

${ }^{33}$ A través de la Ley 22/2009 se añadió financiación a las CC.AA. con criterios de población dependiente. Concretamente, número de personas potencialmente dependientes y número de personas reconocidas con derecho a prestación registradas en el SISAAD.

34 Informe no 1.035 del Tribunal de Cuentas, pág. 119. una financiación garantista ni continuada como la establecida en el Nivel Mínimo.

El hecho de que la cuantía del Nivel Mínimo esté en función del grado de dependencia de la persona beneficiaria, y no del coste de la prestación 35 , así como las reducidas cuantías establecidas por dicho concepto ${ }^{36}$ repercute en que la carga financiera recaiga "principalmente" en las finanzas autonómicas. La brecha entre el Nivel Mínimo y el coste de las prestaciones se ha ido incrementando a lo largo de los últimos cuatro años, especialmente, a partir de 2013 por la reducción de las cuantías del Nivel Mínimo establecidas en las medidas de estabilidad presupuestaria (Tabla 4). Así, si en 2011 la cobertura del Nivel Mínimo representaba el $20,85 \%$ del gasto de las prestaciones, en 2014 desciende al $17,34 \%$.

Tabla 4. Estimación del peso de la financiación del Nivel Mínimo sobre el coste de las prestaciones

\begin{tabular}{|l|c|c|c|c|}
\cline { 2 - 5 } \multicolumn{1}{c|}{} & 2011 & 2012 & 2013 & 2014 \\
\cline { 2 - 5 } \multicolumn{1}{c|}{} & \multicolumn{4}{c|}{ Millones euros } \\
\hline Nivel mínimo (1) & $1.134,98$ & $1.287,18$ & $1.087,18$ & $1.087,18$ \\
\hline $\begin{array}{l}\text { Suplementos de } \\
\text { credito }\end{array}$ & 202,19 & 117,31 & 120 & 54,68 \\
\hline $\begin{array}{l}\text { TOTAL ingresos } \\
\text { Nivel Mínimo }\end{array}$ & $1.337,17$ & $1.404,49$ & $1.207,18$ & $1.141,86$ \\
\hline \multicolumn{5}{|c|}{} \\
\hline $\begin{array}{l}\text { Gasto total } \\
\text { prestaciones }\end{array}$ & $6.412,50$ & $6.705,24$ & $6.574,38$ & $6.583,27$ \\
\hline $\begin{array}{l}\text { \% de ingresos/ } \\
\text { gastos }\end{array}$ & 20,85 & 20,95 & 18,36 & 17,34 \\
\hline
\end{tabular}

(1) Sin Ceuta, ni Melilla.

Fuente: PGE, SISAAD y elaboración propia.

Sin embargo, las autonomías no soportan el $80 \%$ del coste de las prestaciones como en un principio parece deducirse del análisis sino que una parte del gasto es recuperada a través de las contribuciones de los usuarios. Así, sí “hipotéticamente” la cifra global de los copagos se situara en el $20 \%$ del coste de las prestaciones, en el ejercicio 2014 la distribución de la financiación del gasto seria la siguiente: AGE el $17,3 \%$, CC.AA. el $62,7 \%$ y los usuarios el $20 \%$, con lo cual los usuarios contribuirían en mayor proporción que la AGE.

La financiación por beneficiario que cada comunidad autónoma recibe del Nivel Mínimo no es homogénea entre los territorios ya que depende no sólo de la estructura de los grados de dependencia de las personas atendidas sino, también, de un índice corrector de penalización/ premio (RD 1050/2013), por tener más o menos prestaciones económicas de

${ }^{35}$ La cobertura del coste de la prestación oscila entre el $7 \%$ y el $22 \%$ dependiendo del coste de la prestación y del grado de dependencia del usuario.

${ }^{36}$ Cuantías mensuales: Grado 3-2, 231,82 €; Grado 3-1, 157,26€; Grado 3, 177,84€; Grado 2-2, 89,38€; Grado 2-1, 61,34€; Grado 2, 82,84€; Grado 1-2, 52,06€; y Grado 1, 44,33€. 
la PECEF. Ello distorsiona que la distribución del Nivel Mínimo sea equitativa entre los territorios.

Las cifras ponen de relieve el escaso peso que representa la financiación global del Nivel Mínimo sobre el coste de las prestaciones, la perversión del sistema de distribución del Nivel Mínimo y, por ello, la necesidad de una reforma del sistema de financiación del SAAD que garantice unos ingresos suficientes para cubrir las necesidades de las personas en situación de dependencia y una distribución equitativa de los recursos financieros entre los territorios.

\section{El impacto del RDL 20/2012 en el gasto de la atención a la dependencia}

En este apartado, por una parte se describe la evolución del gasto público en la atención a la dependencia en los últimos tres ejercicios y, por otra parte, se hace una valoración global del ahorro presupuestario que han supuesto las medidas de estabilidad presupuestaria contenidas en el RDL 20/2012.

Cabe recordar que el nuevo modelo asistencial que crea la LAPAD coexiste con la acción protectora de la Seguridad Social que ya venía asumiendo la asistencia ${ }^{37}$ a las personas en edad laboral con discapacidad sobrevenida que participasen activamente en el mercado de trabajo en el momento de la contingencia, así como aquellas otras prestaciones asistenciales que tengan la finalidad de subsidiar a la persona dependiente o a su familia de la carga económica que supone estar en una situación de dependencia. Asimismo, se incluye la acción protectora a las persones en situación de dependencia de las Mutualidades ${ }^{38}$ de los funcionarios del Estado (clases pasivas). Estas prestaciones son las denominadas "prestaciones de análoga naturaleza" (art. 31 de la Ley 39/2006) y son incompatibles con las prestaciones reconocidas por la LAPAD. Por ello, el gasto total en atención a la dependencia es la suma del gasto de la LAPAD y el gasto de los otros regímenes de protección social en la atención a la dependencia.

\subsection{Los recortes en el gasto público en las prestaciones de la LAPAD}

La aplicación del conjunto de medidas del RDL 20/2012 ha dado sus frutos en la contención del crecimiento del gasto público en las prestaciones de la LAPAD. La principal medida de contención del

${ }^{37}$ Son los complementos de ayuda a tercera persona en las prestaciones de gran invalidez, prestación familiar por hijo a cargo con discapacidad, así como de las prestaciones de servicios sociales en materia de reeducación y rehabilitación a personas con discapacidad y asistencia a personas mayores.

${ }^{38} \mathrm{Se}$ incluye MUFACE (Mutualidad general de funcionarios civiles del Estado), ISFAS (Instituto social de las fuerzas armadas) y MUGEJU (Mutualidad general judicial). gasto ha sido la de posponer tres años la entrada de los beneficiarios con dependencia moderada (Grado 1), cuyo ahorro se estima en cuatro mil millones de euros, aproximadamente. Asimismo, dichas medidas han tenido efecto en la contención del gasto en las prestaciones a las personas ya beneficiarias del Sistema.

La principal característica de los presupuestos en los tres ejercicios siguientes a la fecha de la entrada en vigor de los recortes del RDL 20/2012 (agosto 2012) es su estabilidad tanto en el gasto como en el número de prestaciones y beneficiarios.

En cuanto al número de prestaciones, se observa un ligero descenso en los dos últimos ejercicios, siendo un poco más acentuado en el 2014, aunque la principal característica es la reestructuración entre ellas, perdiendo peso la PECEF y aumentando el de las prestaciones en servicios. Entre 2012 y 2014, la PECEF ha disminuido en 28.995 prestaciones, posiblemente debido a la medida de penalización 39 aplicada a las CC.AA. que continuaran promoviendo dicha prestación.

Otras prestaciones en descenso son las del servicio de ayuda a domicilio y la de teleasistencia, prestaciones que hasta ese momento eran proporcionadas por empresas controladas por las Corporaciones Locales. El descenso de las prestaciones del servicio de ayuda a domicilio no se debe tanto a una disminución en cuanto al tipo de prestación, sino a una reorientación del proveedor del servicio, pasando de ser prestados por entes locales (servicio público) a empresas privadas "acreditadas", no incluidas en la red pública pero que atienden a las personas beneficiarias de la LAPAD con prestación económica vinculada. Este mismo proceso se da en la sustitución de la PECEF por servicios, los cuales en su mayoría son servicios de ayuda a domicilio prestados por empresas privadas "acreditadas". De ahí que la "prestación económica vinculada a servicios” sea la prestación que ha tenido, en valores absolutos, mayores incrementos, tanto en 2013 como en 2014.

En cambio, la disminución de la prestación de teleasistencia, que se visualiza a partir de 2013 , es un reflejo de la retirada ${ }^{40}$ de la subvención estatal a las Corporaciones Locales para la prestación de este tipo de servicios (Tabla 5). Ello da lugar a pasar de un servicio prácticamente gratuito a otro de "pago", lo cual produjo, en la mayoría de los casos, una renuncia de las personas beneficiarias a este tipo de servicio, redundando en un empeoramiento de la atención a las personas en situación de dependencia.

39 Penalización a través de recibir una cantidad menor del Nivel Mínimo si el peso de la PECEF de la comunidad autónoma correspondiente fuera superior al de la media del conjunto de las CC.AA.

${ }^{40} \mathrm{http}: / /$ cadenaser.com/ser/2012/11/24/sociedad/1353726806 850215.html. 
Tabla 5. Evolución de las prestaciones. 2012-2014

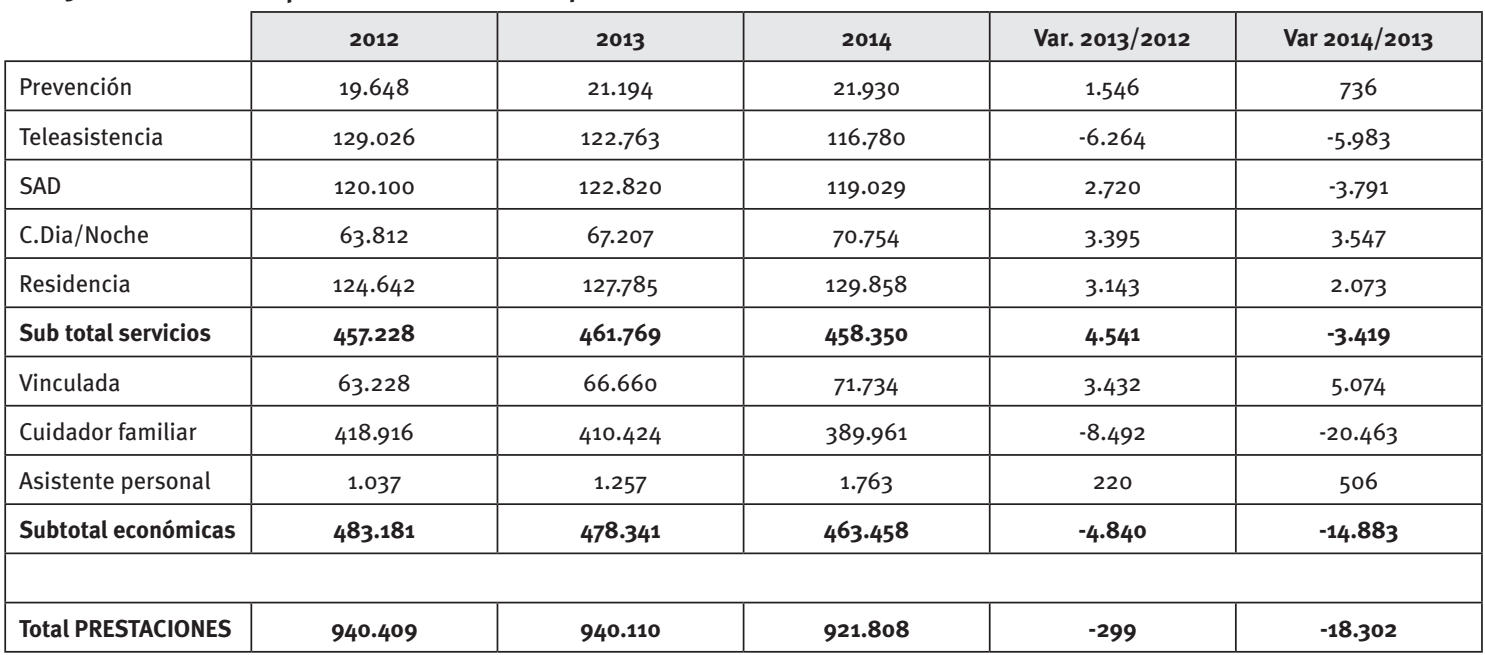

Nota: Las cifras de prestaciones son el promedio del año.

Fuente: SISAAD y elaboración propia.

Tabla 6. Evolución del gasto estimado en prestaciones de la LAPAD. Periodo 2012 a 2014

\begin{tabular}{|c|c|c|c|c|c|}
\hline & 2012 & 2013 & 2014 & Var. 2013/2012 & Var 2014/2013 \\
\hline & \multicolumn{3}{|c|}{ (en millones euros) } & \multicolumn{2}{|c|}{ (en \%) } \\
\hline Gasto servicios & $3.805,73$ & $4.044,14$ & $4.113,25$ & 6,26 & 1,71 \\
\hline Gasto servicios reclasificados (1) & 409,09 & 427,67 & 465,85 & 4,54 & 8,93 \\
\hline Gasto PECEF & $1.657,46$ & $1.451,49$ & $1.388,00$ & $-12,43$ & $-4,37$ \\
\hline Total GASTO Prestaciones & $5.872,27$ & $5 \cdot 923,30$ & $5 \cdot 967,10$ & 0,87 & 0,74 \\
\hline Gastos gestión + atrasos retroactividad & 832,97 & 651,08 & 616,17 & $-16,37$ & 2,84 \\
\hline TOTAL GASTO LAPAD & $6.705,24$ & $6.574,38$ & $6.583,27$ & $-1,27 \%$ & 0,95 \\
\hline
\end{tabular}

(1) Incluye la prestación económica vinculada y la asistencia personal.

Fuente: SISAAD, Informes personas mayores y elaboración propia.

Las cifras de la evolución del gasto estimado en prestaciones muestran que las medidas de estabilidad presupuestaria han sido un éxito (Tabla 6). En general, el gasto total ${ }^{41}$ en prestaciones de la LAPAD prácticamente se mantiene constante durante los tres ejercicios analizados (2012-2014) alcanzando cifras de, alrededor de 6.000 millones de euros, pero con una reclasificación del mismo, aumenta el gasto en servicios y desciende el gasto en PECEF, lo cual es consecuente con los objetivos perseguidos en el RDL 20/2012. Se observa que, a pesar de que el número de prestaciones ha descendido en el 2014 respecto al ejercicio anterior (en 18.302), el gasto no ha disminuido ya que las nuevas prestaciones se realizan a través de servicios que tiene un coste más elevado que el coste de las PECEF, lo cual incrementa el gasto público.

El gasto total estimado en la LAPAD, que incluye
${ }^{41}$ Las cifras del gasto son estimadas por la autora debido a la falta de publicidad de dichos datos. La estimación se realiza según el método del "coste efectivo" de las prestaciones estimado según la información contenida en el Informe Mayores 2013 que, en definitiva, son datos proporcionados por las CC.AA. Se han mantenido constantes las cifras del coste durante los tres ejercicios analizados. atrasos pagados en el ejercicio derivados de la retroactividad de las prestaciones económicas antes de su modificación en 2010 (RDL 8/2010), muestra el mismo comportamiento que el gasto en prestaciones; se mantiene constante en los años 2013 y 2014 con un ligero descenso respecto al $2012(-1,27 \%)$. Las cifras del gasto total se sitúan, alrededor de 6.500 millones de euros. Las Administraciones autonómicas disponen de hasta ocho años para satisfacer los retrasos devengados por la retroactividad de las prestaciones económicas.

Los indicadores del gasto, en el 2014, muestran que el coste medio anual de las prestaciones es de 6.473 euros y el coste medio anual por beneficiario es de 8.122 euros (Tabla 7). La diferencia se debe a que una persona puede recibir más de una prestación, tal como muestra el ratio "prestaciones por persona beneficiaria” que se sitúa en 1,25. Este indicador se mantiene constante a lo largo de los años. La evolución de los indicadores del "gasto por prestación” y "gasto por persona beneficiaria” ilustra un ligero aumento a lo largo de los años, pero ello no se debe tanto a que se haya dedicado mayor presupuesto como a la ligera disminución en el número de prestaciones y en el número de beneficiarios en dicho periodo. 
Tabla 7. Indicadores económicos de las prestaciones de la LAPAD

\begin{tabular}{|l|c|c|c|}
\cline { 2 - 4 } \multicolumn{1}{c|}{} & $\mathbf{2 0 1 2}$ & $\mathbf{2 0 1 3}$ & $\mathbf{2 0 1 4}$ \\
\hline Número prestaciones & 940.409 & 940.110 & 921.808 \\
\hline Número beneficiarios & 751.864 & 748.612 & 734.690 \\
\hline $\begin{array}{l}\text { Coste / prestación } \\
(€ / \text { año })\end{array}$ & 6.244 & 6.301 & 6.473 \\
\hline $\begin{array}{l}\text { Coste/ beneficiario } \\
(€ / \text { año })\end{array}$ & 7.810 & 7.912 & 8.122 \\
\hline $\begin{array}{l}\text { Ratio prestaciones/ } \\
\text { beneficiarios }\end{array}$ & 1,25 & 1,26 & 1,25 \\
\hline
\end{tabular}

Nota: Los costes y el ratio se calculan sobre el gasto en prestaciones. Fuente: SISAAD, Informe Mayores (2011 y 2013) y elaboración propia.

\subsubsection{El gasto en prestaciones de la LAPAD desglosado por autonomías}

El esfuerzo económico realizado por cada comunidad autónoma ${ }^{42}$ se mide aquí a través de un indicador "externo" 43 con el fin de visualizar las diferencias entre ellas. El indicador utilizado es el "gasto / habitante dependiente", entendiendo por gasto el realizado por la comunidad autónoma en cada uno de los años seleccionados -2010, 2013 y 2014-, y por habitantes dependientes el número de personas potencialmente dependientes en cada comunidad autónoma según la encuesta EDAD_2008, cuya cifra fue utilizada para asignar financiación a través del Nivel Acordado. Se toma como base el año 2010 para tener una referencia más distante que permita ver hasta qué punto el gasto ha variado.

El resultado del indicador muestra que la media anual del gasto por habitante dependiente, en 2010 era de $\mathbf{2 . 4 1 7}$ euros, en 2013 de $\mathbf{2 . 7 5 7}$ euros y en 2014 de 2.777 euros. Así, se percibe que el crecimiento del gasto en prestaciones de la LAPAD se ha mantenido prácticamente constante entre 2013 y 2014 y el crecimiento del gasto se realizó con anterioridad a las medidas de estabilidad presupuestaria.

Los resultados se pueden apreciar en la Tabla 8 y el Gráfico 5, donde se pone de relieve que las CC.AA. con mayor presupuesto en el programa de “Atención a la dependencia”, en 2014, son La Rioja y el País Vasco, seguidas de Cantabria y Comunidad de Madrid. Por el contrario, las CC.AA. con menor presupuesto son Canarias, Valencia y Ceuta-Melilla.

Tabla 8. Gasto por habitante dependiente, por autonomías (en euros). 2010, 2013 y 2014

\begin{tabular}{|c|c|c|c|}
\hline & 2010 & 2013 & 2014 \\
\hline ANDALUCIA & 2.577 & 2.515 & 2.364 \\
\hline ARAGON & 2.768 & 2.147 & 2.108 \\
\hline ASTURIAS & 1.743 & 1.954 & 1.908 \\
\hline ISLAS BALEARES & 1.531 & 1.872 & 2.025 \\
\hline CANARIAS & 750 & 959 & 1.032 \\
\hline CANTABRIA & 4.179 & 4.559 & 4.640 \\
\hline CASTILLA Y LEON & 2.731 & 3.569 & 3.546 \\
\hline CASTILLA-LA MANCHA & 2.965 & 2.909 & 2.930 \\
\hline CATALUÑA & 2.907 & 3.508 & 3.587 \\
\hline COMUNIDAD VALENCIANA & 1.462 & 1.465 & 1.381 \\
\hline EXTREMADURA & 2.260 & 2.565 & 2.795 \\
\hline GALICIA & 1.341 & 1.999 & 1.920 \\
\hline COMUNIDAD DE MADRID & 2.798 & 3.810 & 4.019 \\
\hline MURCIA & 1.642 & 1.917 & 2.181 \\
\hline NAVARRA & 2.722 & 2.857 & 2.897 \\
\hline PAIS VASCO & 4.697 & 5.542 & 5.920 \\
\hline LA RIOJA & 6.294 & 6.671 & 6.403 \\
\hline CEUTA Y MELILLA & 1.547 & 1.506 & 1.475 \\
\hline MEDIA & 2.417 & 2.757 & 2.777 \\
\hline
\end{tabular}

Fuente: Edad_ 2008, Nivel acordado y elaboración propia.

${ }^{42}$ A efectos del estudio se asimila las ciudades autónomas de Ceuta y Melilla como Comunidades autónomas.

${ }^{43}$ Que sea el mismo indicador en términos homogéneos para todas las CC.AA. y que mida un input externo a la actividad de cada comunidad autónoma. 
Andalucía

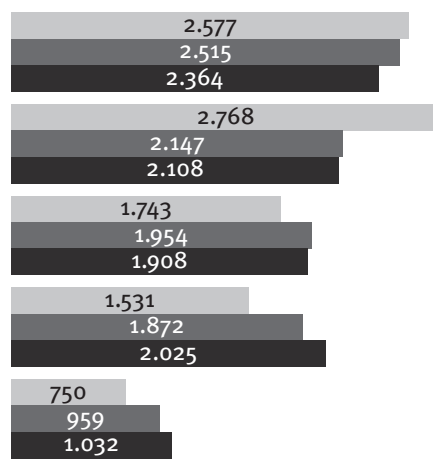

Islas Baleares

Canarias

Cantabria

Castilla y León

Castilla-La Mancha

Cataluña

Comunidad Valenciana

Extremadura

Galicia

Comunidad de Madrid
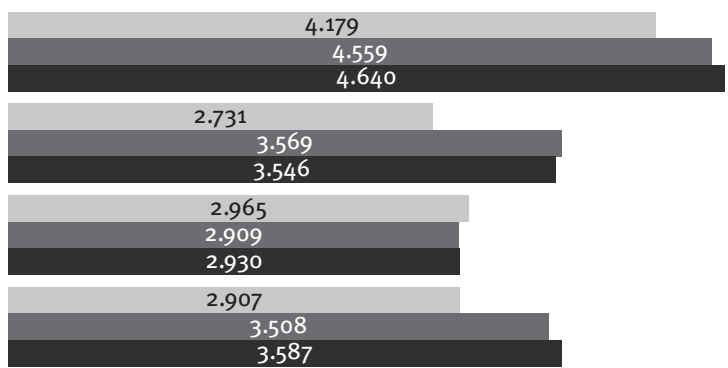

3.587
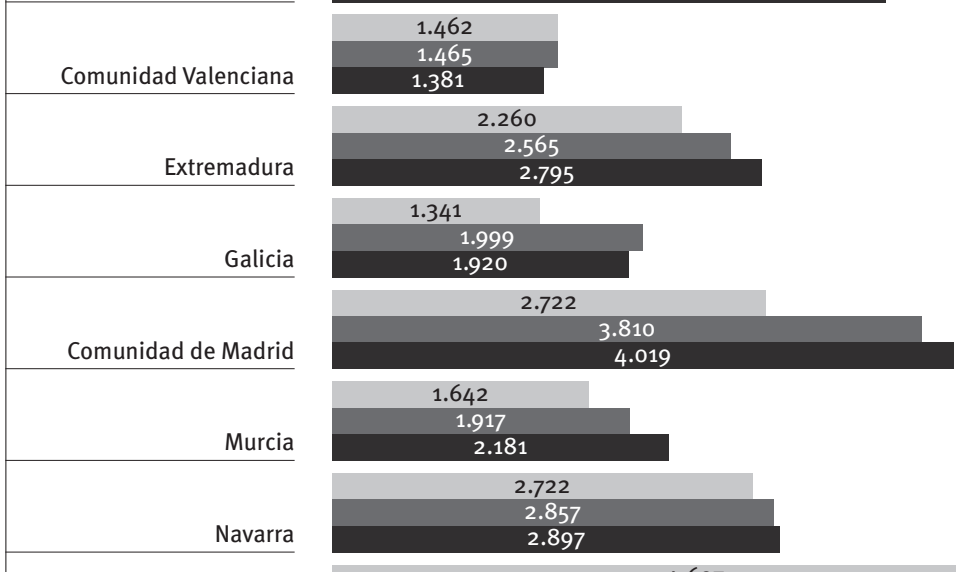

País Vasco
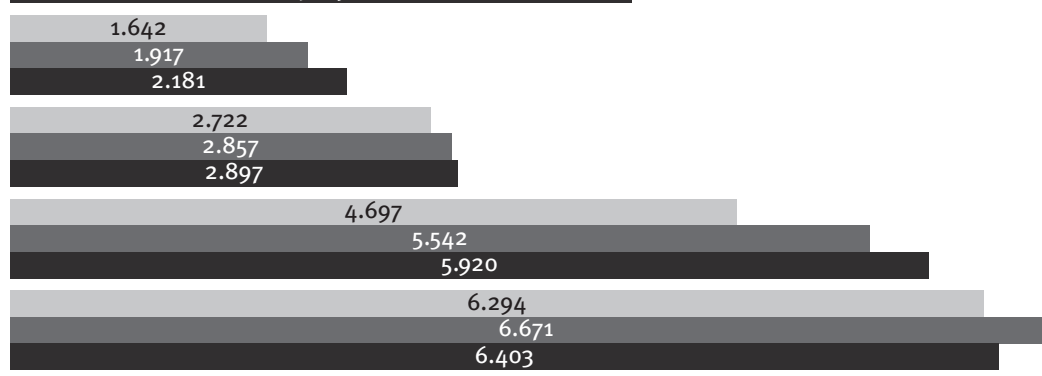

La Rioja

Ceuta y Melilla

Media

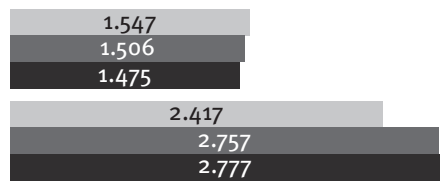

2010

2013

2014

Fuente: SISAAD y elaboración propia.

\subsubsection{El gasto en atención a la dependencia comparado con otros países}

La política de protección social en España se amplió con la entrada en vigor de la LAPAD. El gasto público que se estimaba alcanzar en 2015 era del $1 \%$ del PIB, cifra bastante inferior a la media europea $(1,8 \%$ del
PIB) pero bastante superior a la alcanzada después de las medidas de estabilidad presupuestaria (o,68\% del PIB).

La Tabla 9 muestra diferentes conceptos de gastos relacionados con la atención a la dependencia. El gasto más importante es el efectuado en 
prestaciones de la LAPAD, el cual representa casi el $92 \%$ del total; se añade un pequeño importe en concepto de "otros gastos relacionados con la atención a la dependencia” los cuales aparecen en los Presupuestos Generales del Estado como son los gastos en centros estatales de referencia y un pequeño gasto en inversión y, finalmente, figuran los gastos de "otros regímenes de protección social", que comprende el gasto realizados por la Seguridad Social y Mutualidades de funcionarios del Estado en prestaciones relacionadas con la atención a las personas en situación de dependencia.

Tabla 9. Evolución del gasto global atención a la dependencia

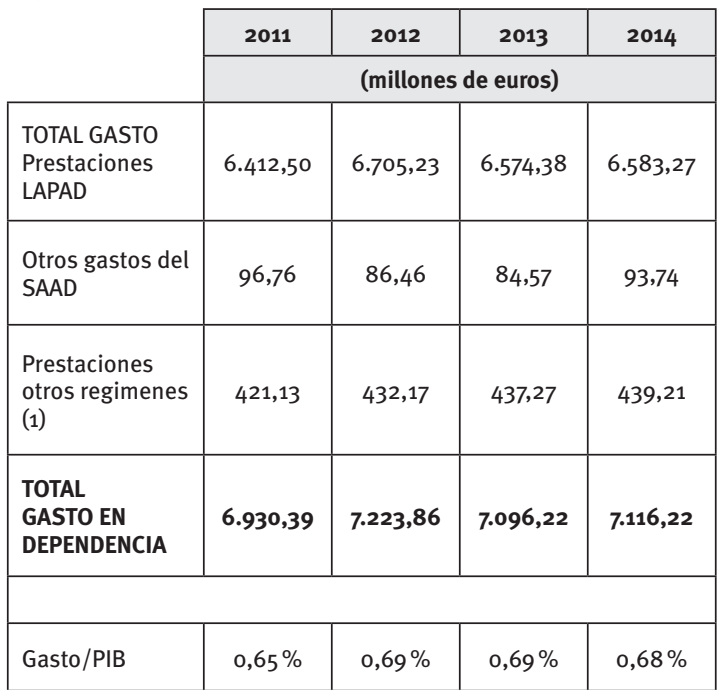

(1) Gasto prestaciones análoga naturaleza de: Seguridad Social y Mutualidades funcionarios del Estado.

Nota: PIB a precios corrientes base 2010. INE. Contabilidad Nacional de España

Fuente: SISAAD, Estadísticas Seguridad Social, Memoria Mutualidades y elaboración propia

La evolución del indicador "gasto/ PIB" muestra el gasto en atención a la dependencia se ha mantenido prácticamente constante en los tres ejercicios siguientes al de las medidas de estabilidad presupuestaria (2012-2014), alcanzando la cifra de, entre 0,68 y $0,69 \%$ del PIB. La comparación con el gasto del ejercicio anterior al de los recortes (2011) muestra que en la primera mitad del 2012 se produjo un cierto incremento del mismo cuya cifra se estabilizó posteriormente.

El Gráfico 6 muestra los valores disponibles en 16 de países de la UE según los datos de la OCDE (Health Statistics) ${ }^{44}$ referidos al año 2011, los cuales resultan en un gasto medio del 1,6\% del PIB. Sin embargo, otras estadísticas como la utilizada por la Comisión europea en su Informe sobre el envejecimiento (AWG, 2012) señalan que el gasto medio estimado de los países de la UE-27 es del 1,8\% del PIB. La comparación

44 OECD Health Statistics 2013. http://dx.doi.org/10.1787/ health-data-en. del gasto en España, alrededor del 0,7 del PIB ${ }^{45}$, muestra la gran distancia que nos separa respecto a la de otros países europeos y de la media de la UE-27.

Gráfico 6. Gasto en cuidados de larga duración en varios países de la UE (en \% del PIB)

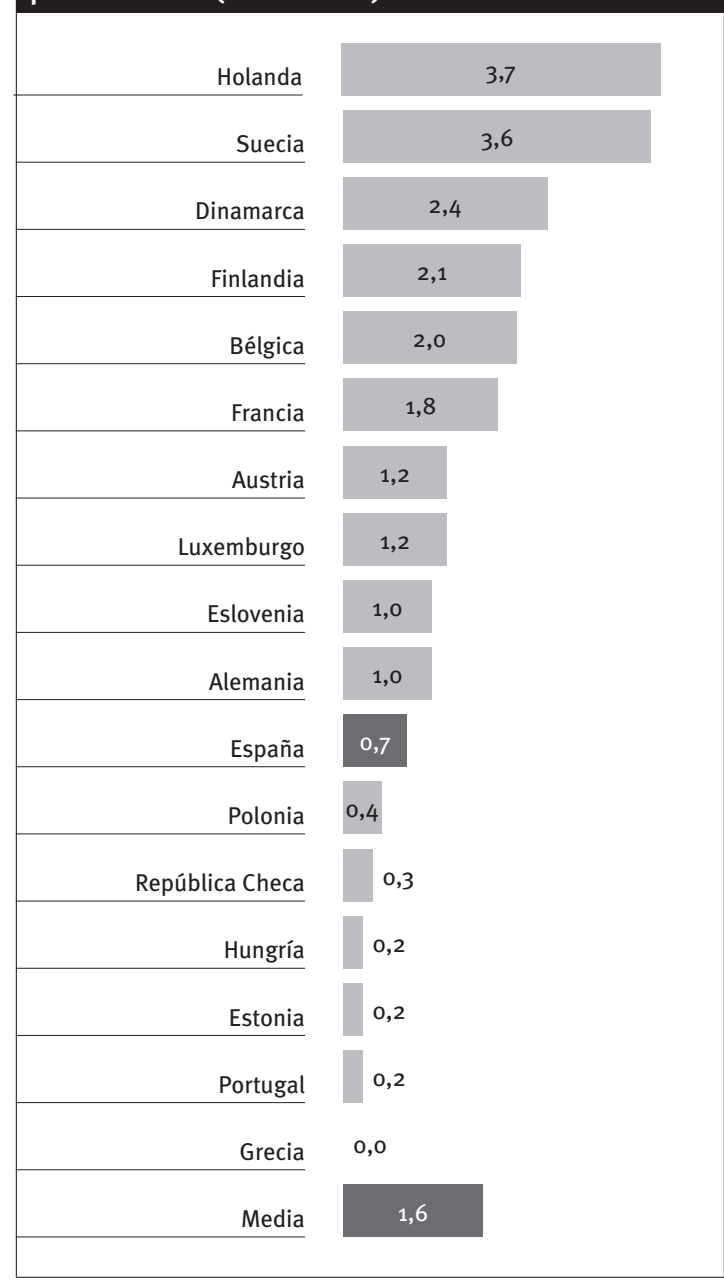

Fuente: OCDE: Health Statistics. Datos 2011

\subsection{Valoración global del ahorro resultante de las medidas de estabilidad presupuestaria}

Las reformas introducidas en el RDL 20/2012, Presupuestos Generales del Estado y otras normas colaterales están dirigidas a contener el gasto público en todos los niveles de financiación pública cuyos resultados empiezan a visualizarse en 2012 y se mantiene en los tres ejercicios siguientes. A continuación se realiza una estimación del ahorro presupuestario en los presupuestos del conjunto de las administraciones públicas - administración estatal y autonómicas - en los tres años siguientes desde la efectividad del RDL 20/2012 incluyendo el ahorro de aquellas reformas anteriores a dicha

45 Se observa que la cifra que figura en el Gráfico (0,7\%) se ha redondeado hacia arriba respecto a la que sale de las estimaciones presentadas. 
fecha que están relacionadas con la LAPAD. Un mayor detalle de los resultados que se presentan a continuación se pueden consultar en VII Informe FOESSA, (Montserrat Codorniu, 2014).

La medida con mayor impacto presupuestario ha sido la de posponer la entrada de las personas con dependencia moderada (Grado 1) durante tres años, de agosto 2012 a julio de 2015, la cual se estima que ha supuesto un ahorro para el conjunto de las autonomías de 4.000 millones de euros, aproximadamente.

Otro frente de contención del gasto público ha sido la reducción, tanto de las intensidades de las prestaciones (ayuda a domicilio, principalmente), como las cuantías de las prestaciones económicas. El ahorro presupuestario por estos dos conceptos ha sido de 1.145 millones de euros, aproximadamente.

La disminución de las cuantías del Nivel Mínimo de financiación a las CC.AA. es otro de los conceptos que impactan directamente en la disminución del gasto público, ya que el resultado es que las Comunidades dedican un importe presupuestario menor para la atención a la dependencia. El ahorro estimado es de 428 millones de euros.

Otras medidas no incluidas en el RDL 20/2012, pero que tienen el mismo propósito de reducir el gasto público, son la supresión de la bonificación de la cuota de la Seguridad Social a los cuidadores familiares y la suspensión del Nivel Acordado. El impacto de la primera medida no solo es de tipo económico sino que hay un daño colateral por dejar sin protección (aunque pequeña) a muchas cuidadoras (la mayoría son mujeres) cuya cotización les permitía ganar un periodo de cotización para la jubilación. La segunda medida solo tiene un impacto económico, al financiar en menor medida a las CC.AA. La suma de ambas medidas ha supuesto un ahorro de 3.000 millones de euros, aproximadamente.
Por último, el impacto del aumento de los copagos es el dato menos contrastable porque, como se ha dicho anteriormente, hay un total "oscurantismo" por parte de las administraciones públicas en informar sobre los importes recaudados de los usuarios. Teniendo en cuenta el hipotético incremento de recaudación con la aplicación del nuevo modelo de copago acordados por el Consejo Territorial de 10/7/2012, del cual se estima un incremento medio anual de 59 millones de euros, resulta un ahorro presupuestario de 148 millones de euros en el periodo considerado.

Tal como se puede ver en la Tabla 10, el ahorro global para las finanzas de las Administraciones públicas de las medidas de estabilidad presupuestaria, en el periodo agosto 2012 a julio 2015, se estima en 8.745 millones de euros, equivalente al o,83\% del PIB (base 2014), lo que equivale al gasto global en atención a la dependencia de un ejercicio entero incluyendo la atención a las personas con dependencia moderada.

\section{Conclusiones}

Las medidas de estabilidad presupuestaria en materia de atención a la dependencia, a través del RDL 20/2012, han supuesto la "refundación de la LAPAD”, modificando toda la estructura asistencial al reducir la intensidad y la calidad de las prestaciones, disminuyendo la financiación del nivel mínimo garantizado y exigiendo a los usuarios un mayor nivel de contribución a través de los copagos.

El objetivo de reducir el gasto público en la atención a la dependencia mediante la refundación de la LAPAD y otras normas colaterales se ha alcanzado con éxito. El gasto público se ha mantenido prácticamente constante en los tres últimos ejercicios (2012, 2013 y 2014), pero se ha reestructurado la proporción entre las prestaciones, de forma que disminuye el gasto en PECEF y aumenta el gasto en servicios, cumpliendo

Tabla 10. Ahorro estimado de las principales medidas de estabilidad presupuestaria

\begin{tabular}{|c|c|c|c|c|c|}
\hline & $\begin{array}{l}2012 \text { (mitad } \\
\text { año) }\end{array}$ & 2013 & 2014 & $\begin{array}{l}2015 \text { (mitad } \\
\text { año) }\end{array}$ & $\begin{array}{l}\text { TOTAL periodo } \\
(\mathrm{M} €)\end{array}$ \\
\hline & \multicolumn{5}{|c|}{ (en millones de euros) } \\
\hline Retraso entrada beneficiarios Grado 1 & 432 & 1.002 & 1.662 & 875 & 3.971 \\
\hline $\begin{array}{l}\text { Reducir intensidades servicios y prestaciones } \\
\text { económicas }\end{array}$ & 150 & 399 & 397 & 199 & 1.145 \\
\hline Disminución importe Nivel Mínimo & 68 & 145 & 143 & 72 & 428 \\
\hline $\begin{array}{l}\text { Supresión bonificacion cuota Seg. Social } \\
\text { cuidadores + suspensión Nivel Acordado }\end{array}$ & 920 & 889 & 829 & 415 & 3.053 \\
\hline Aumento de los copagos & & 59 & 59 & 30 & 148 \\
\hline Total estimación AHORRO (M€) & 1.570 & 2.494 & 3.091 & 1.589 & 8.745 \\
\hline Ahorro/PIB (M€) & $0,15 \%$ & $0,24 \%$ & $0,30 \%$ & $0,15 \%(*)$ & $0,83 \%(*)$ \\
\hline
\end{tabular}

(*)Porcentajes estimados según PIB 2014.

Nota:PIB a precios corrientes base 2010. INE.Contabilidad Nacional de España.

Fuente: SISAAD, disposiciones normativas y elaboración propia. 
uno de los objetivos de la reforma de la LAPAD, aunque ello haya significado dejar sin prestación a más de medio millón de personas con dependencia moderada y contener la entrada al Sistema de personas en situación de dependencia que por Ley ya podían ser beneficiarios. El ahorro estimado que ha supuesto en las finanzas públicas la aplicación de las medidas de estabilidad presupuestaria, en los tres primeros años de su aplicación, es de 9.000 millones de euros, equivalente al $0,83 \%$ del PIB. Con el dinero ahorrado se hubiera podido pagar el gasto global de prestaciones de un ejercicio entero, incluyendo la atención a las personas con dependencia moderada.

La refundación de la LAPAD persigue aumentar la oportunidad de negocio de los sectores productivos relacionados con la dependencia, tal como declara el preámbulo del RDL 20/2012, reafirmando la mercantilización de los servicios públicos y abriendo nuevas cuotas de mercado a las empresas privadas "acreditadas" que atienden a personas beneficiarias de la dependencia a través de las prestaciones económicas vinculadas. No es baladí que el mayor incremento de los servicios, en los tres últimos ejercicios, haya sido en las empresas "acreditadas", las cuales escapan del control de calidad impuesto al resto de los servicios concertados sin que ello signifique que, en todos los casos, dicho nivel sea inferior. Por otra parte, la calidad asistencial de los servicios públicos está amenazada por los recortes presupuestarios. La Administración, a cambio de no aumentar los precios de los servicios, no siempre exige los estándares de calidad pactados. Ello se materializa con la existencia de ratios de personal "no adecuados", trabajadores sin la debida cualificación profesional y la precariedad de los empleos, lo cual afecta mayoritariamente a las mujeres. Se echa en falta un sistema de indicadores que mida la calidad asistencial de los servicios públicos en todos sus aspectos, abarcando también los servicios de las empresas acreditadas.

Existe indefensión de los ciudadanos ante ciertas "irregularidades" de las Administraciones públicas en la concesión de las prestaciones, por ejemplo, manteniendo a los ciudadanos en el "limbo", en "largas listas de espera" o, simplemente, "congelando" durante dos años el pago de una prestación reconocida, como es el caso de la prestación económica de cuidados en el entorno familiar (PECEF), lo cual constituye un auténtico atropello a los derechos de los beneficiarios. El desmantelamiento de la PECEF se hace sin reconocer que se deja un vacío en el derecho de los ciudadanos a ser cuidados en su propio domicilio por cuidadores debidamente capacitados que permitan ofrecer un servicio continuado y de calidad alternativo al servicio residencial. Si el objetivo es mejorar la calidad del cuidado que recibe la persona, sorprende que el servicio "sustitutivo" más idóneo - servicio de ayuda domiciliaria (SAD) - se preste con solo una hora y media de trabajador/a familiar como promedio diario cuando se supone que una persona en situación de dependencia grave o muy grave requiere cuidados continuados dos o tres veces al día, según la propia definición de la LAPAD. Con una prestación de $\tan$ baja intensidad es difícil pensar que el SAD esté siendo un servicio "sustitutivo" efectivo, y de calidad, de la prestación de cuidados familiares.

Mientras que por un lado se desmantela la prestación de cuidados en el entorno familiar, por el otro lado se promueve la prestación económica vinculada al servicio, la cual permite una vía "rápida" de acceso a los servicios que solo es accesible a las personas más pudientes económicamente. Con estas actuaciones, el ejercicio de responsabilidad pública, de asegurar la igualdad de todos los ciudadanos a la hora de acceder a las prestaciones públicas en las mismas condiciones, se tambalea, propiciando la doble puerta de entrada al Sistema y la estigmatización de los servicios públicos "propiamente dichos".

Uno de los instrumentos para rebajar el gasto público es aumentar la recaudación vía copagos, aunque en las estadísticas oficiales se siga utilizando el gasto "total" como indicador de la contribución del Estado, omitiendo la cantidad recaudada por ese concepto. El sistema de copagos en la LAPAD tiene una finalidad recaudatoria importante, el cual se reafirma, e incluso se incrementa, con la refundación de la LAPAD. El modelo de copagos aprobado por el Consejo Territorial de 2012 es altamente inequitativo y ejerce una elevada presión recaudatoria sobre las personas con rentas medias-bajas, llegando a exigir cuotas del $80 \%$ y del $90 \%$ de sus rentas, pudiendo incluso sobrepasar la totalidad de sus ingresos líquidos si disponen de patrimonio. Se da la paradoja de que la inclusión del valor del patrimonio para determinar la capacidad económica del usuario tiene un efecto contrario al objetivo deseado, incrementando aún más la inequidad entre los usuarios. La excesiva presión de los copagos y la posible reducción de la herencia por las deudas contraídas con la Administración, ejercen un efecto perverso en los objetivos asistenciales de la Ley, provocando la "contención" y la "exclusión voluntaria" del Sistema de aquellas personas con menos recursos económicos. Por ello, se debería reformular la finalidad y el modelo del copago para evitar las inequidades y los efectos perversos descritos.

El nivel de colaboración financiera de la AGE con las administraciones autonómicas a través del Nivel Mínimo garantizado es insuficiente para cubrir la mitad del "coste neto" de las prestaciones gestionadas por las autonomías. El hecho de que la cuantía del Nivel Mínimo esté en función del grado de dependencia de la persona beneficiaria, y no del coste de la prestación, así como las reducidas cuantías establecidas por dicho concepto repercute en que la carga financiera recaiga "principalmente" en las finanzas autonómicas. La brecha entre el Nivel Mínimo y el coste de las prestaciones se ha ido incrementando a lo largo de los últimos tres años. Así, si en 2011 la cobertura del Nivel 
Mínimo representaba el 20,85\% del gasto de las prestaciones, en 2014 desciende al 17,34\%. Ello supone una aportación menor que la realizada por los usuarios a través de los copagos, entre un $20 \%$ y un $23 \%$. Por ello, es necesaria una reforma del sistema de financiación que garantice unos ingresos suficientes al Sistema y evite los desequilibrios financieros territoriales así como la excesiva cuantía de los copagos de los usuarios.

La LAPAD ha supuesto un impulso importante en la mejora de la protección social para las personas en situación de dependencia, al pasar de un sistema asistencial a un sistema universal, lo cual ha significado un esfuerzo financiero importante en el conjunto de las Administraciones públicas situando el "gasto/PIB" en el o,68\% aunque por debajo del que se había previsto inicialmente ( $1 \%$ del PIB), y a un punto porcentual por debajo de la media de los países de la Unión Europea (1,8\% del PIB). Sin embargo, los efectos de las medidas de estabilidad presupuestaria pueden convertir el actual desfase en la protección social a la dependencia en una situación permanente, alejándonos cada vez más de los estándares europeos si no se articulan medidas financieras que aseguren la recuperación de los niveles asistenciales definidos previamente en la LAPAD y no se establece un sistema de indicadores de seguimiento de la calidad asistencial según los parámetros exigidos por la ciudadanía.

Por ello, sería recomendable re-iniciar un debate profundo sobre el sistema de protección social en atención a la dependencia con el fin de asegurar un nivel asistencial eficiente, eficaz y de calidad que evite las exclusiones del Sistema de las personas con derecho a las prestaciones y las desigualdades de trato entre los individuos, así como redefinir el sistema de financiación que permita alcanzar estándares elevados de bienestar social sostenibles a medio y largo plazo. 


\section{Bibliografía}

AEDGSS. Asociación Estatal de Directores y Gerentes de Servicios Sociales (2015): XV dictamen del Observatorio de la Dependencia.

AWG (2015): The 2015 Ageing Report: Economic and Budgetary Projections for the $28 \mathrm{EU}$ Member States (2013-2060), Comisión Europea, Economic Policy Committee's Working Group on Ageing Populations and Sustainability [Ageing Working Group].

- (2012): The 2012 Ageing Report: Economic and Budgetary Projections for the $27 \mathrm{EU}$ Member States (2013-2060), Comisión Europea, Economic Policy Committee's Working Group on Ageing Populations and Sustainability [Ageing Working Group].

GUILLÉN, A. M. (2010): "Desfrosting the Spanish welfare state: The weight of conservative components", en PALIER, B. (ed.), A Long Good Bye to Bismark: The Politics of Welfare Reform in Continental Europe, Amsterdam, Amsterdam University Press.

GUILLÉN, A. M.; y LEÓN, M. (2011): The Spanish Welfare State in European Context, Farnham, Ashgate Publishing.

IMSERSO (2014): Avance de la evaluación 2013 del sistema de la dependencia.

MARBÁN GALLEGO, V. (2012): “Actores sociales y desarrollo de la Ley de la Dependencia”, Revista Internacional de Sociología, no 70 , págs. 375-398.

MARTíN SERRANO, E. (2014): “¿Es todavía posible un sistema de dependencia como motor económico y de empleo?", Actas de la Dependencia, $\mathrm{n}^{\circ} \mathrm{o} 11$.

MARTÍNEZ BUJÁN, R. (2011): “La reorganización de los cuidados familiares en un contexto de migración internacional", Cuadernos de Relaciones Laborales, vol. 29, nํㅜ 1, págs. 93-123.

MINISTERIO DE SANIDAD, POLÍTICA SOCIAL E IGUALDAD (2011a): Informe del Gobierno para la evaluación de la Ley de Promoción de la Autonomía Personal y Atención a la Dependencia [<http://www.dependencia. imserso.es/InterPresent2/groups/imserso/ documents/binario/im_082153.pdfs].

- (2011b): Libro blanco de la coordinación sociosanitaria en España.

MINISTERIO DE TRABAJO Y ASUNTOS SOCIALES (2004): Libro blanco de la dependencia.

MONTSERRAT CODORNIU, J. (2014): "El impacto de la crisis en el sistema de atención a la dependencia: ¿hacia un cambio de modelo?", en VII Informe FOESSA, cap. 5 , págs. 343-351.

(2011): “Copago en la Ley de Promoción de la Autonomía Personal y Atención a las Personas en Situación de Dependencia: costes e impactos en la renta de los usuarios", Papeles de Economía Española, nํㅜ 129, págs. 195-207.

MONTSERRAT CODORNIU, J.; y MONTEJO, I. (2012): “El copago en la Ley de Promoción de la Autonomía Personal y Atención a las Personas en Situación de Dependencia en la reforma del sistema de dependencia: costes y financiación", en Actas de la Dependencia, no 6, págs. 75-99.

MORENO, L. (2012): Crisis y Estado del bienestar. La Europa asocial, Barcelona, Península.

NAVARRO, V. (coord.) (2004): El Estado de bienestar en España, Madrid, Tecnos.

PIERSON, P. (ed.) (2001): The New Politics of the Welfare State, Oxford, Oxford University Press. 
PRADA, M. D.; y BORGE, L. M. (2014): Una aproximación al coste de la dependencia en España y su financiación, Fundación Caser.

RODRÍGUEZ CABRERO, G. (2014): "Transformaciones, cambios institucionales e impactos sociales en el Estado del bienestar", en VII Informe FOESSA, cap. 5, apartado 5.2.

- (2012): "La Ley de la dependencia: ¿una oportunidad perdida en el desarrollo de los derechos sociales?", Gaceta Sindical: Reflexión y Debate, no-19, págs. 319-338.

- (2011a): "Los sistemas públicos europeos de atención a la dependencia”, Actas de la Dependencia, nํㅜ 1 .
- (2011b): "The consolidation of the Spanish Welfare State (1975-2008)”, en GUILLÉN, A. M.; y LEÓN, M. (eds.), The Spanish Welfare State in European Context, Farnham, Ashgate Publishing.

- (2004): “La población dependiente española y sus cuidadores", en CASADO, D. (coord.), Respuestas a la dependencia, Madrid, CCS.

SOSVILLA-RIVERO, S. et al. (2012): “La atención a la dependencia: estimaciones del gasto presupuestario y sus efectos macroeconómicos", Presupuesto y Gasto Público, n- 66, págs. 127-148. 